\title{
TITLE:
}

\section{Inactivation of HeLa cells on nanoporous gold}

\section{$\operatorname{AUTHOR}(\mathrm{S})$ :}

Deguchi, Soichiro; Hakamada, Masataka; Shingu, Jumpei; Sakakibara, Susumu; Sugiyama, Hironobu; Mabuchi, Mamoru

\section{CITATION:}

Deguchi, Soichiro ...[et al]. Inactivation of HeLa cells on nanoporous gold. Materialia 2019, 7: 100370.

ISSUE DATE:

2019-09

URL:

http://hdl.handle.net/2433/261782

\section{RIGHT:}

(c) 2019. This manuscript version is made available under the CC-BY-NC-ND 4.0 license

http://creativecommons.org/licenses/by-nc-nd/4.0/.; The full-text file will be made open to the public on 1 September 2021 in accordance with publisher's 'Terms and Conditions for Self-Archiving'.; This is not the published version. Please cite only the published version.; この論文は出版社版でありません。引用の際には出版社版をご確認ご利用ください。 


\title{
Inactivation of HeLa cells on nanoporous gold
}

Soichiro Deguchi ${ }^{\mathrm{a}}$, Masataka Hakamada ${ }^{\mathrm{a}, *}$, Jumpei Shingu ${ }^{\mathrm{a}}$, Susumu Sakakibara ${ }^{\mathrm{a}}$, Hironobu Sugiyam $^{\mathrm{a}}$ and Mamoru Mabuchi ${ }^{\mathrm{a}}$

${ }^{a}$ Department of Energy Science and Technology, Graduate School of Energy Science, Kyoto University, Yoshidahonmachi, Sakyo, 606-8501 Kyoto, Japan

* Corresponding author at: Department of Energy Science and Technology, Graduate School of Energy Science, Kyoto University, Yoshidahonmachi, Sakyo, 606-8501 Kyoto, Japan

E-mail address: hakamada.masataka.3x@kyoto-u.ac.jp.

\begin{abstract}
Nanoporous metals strongly affect organic matter; however, there is a poor understanding of their effects on cells. The present work shows that HeLa cells on nanoporous gold (NPG) were less active than those on flat gold (FG) with no nanoporous structure. Initially, HeLa cells adhered to the NPG over a period of more than $10 \mathrm{~h}$, then the adhered cells subsequently exhibited apoptosis that was not related to anoikis. ELISA analyses showed that the conformational change of fibronectin was more greatly induced by NPG than FG. First-principles calculations and molecular dynamics simulations were performed to investigate the conformational change in the RGD sequence and the integrin signaling. The simulations suggested that the extended form of integrin, with an open headpiece, was not generated owing to the conformational change of RGD, and the outside-in signals could not be intracellularly transmitted via the integrin binding to the fibronectin on NPG, resulting in cell death.
\end{abstract}

Keywords: HeLa cell, nanoporous gold, cell death, simulation, integrin 


\section{Introduction}

Nanoporous metals exhibit unusual properties that are not seen in the parent bulk metals or other nanostructured materials (such as nanoparticles, nanowires, nanorods, and nanocrystals). For example, piezoelectricity in gaseous $^{1)}$ and electrochemica ${ }^{2,3)}$ environments is a distinguished feature of nanoporous metals that can be applied in sensors and actuators. In addition, nanoporous metals have shown remarkable effects on organic materials: nanoporous gold (NPG) has catalytic properties in $\mathrm{CO}$ and methanol oxidation $^{4-9)}$, although bulk gold does not. In addition, NPG catalytically decomposes methyl orange, while bulk gold does not ${ }^{10)}$. Thus, various unusual properties of nanoporous metals have been reported ${ }^{4-16)}$, however significant scope for further study remains.

One property of nanoporous structures that is not well understood is their effect on cells. Adsorption of proteins on nanoporous structures depends on the network of nanometric pits at the surface ${ }^{17)}$. Cell adhesion is enhanced by nanophase alumina because of the unfolding of the extracellular matrix (ECM) adsorbed on the nanophase alumina ${ }^{18)}$. In addition, cell viability and/or osteoblastic differentiation in osteoblast cells ${ }^{19,20)}$ and mesenchymal stem cells ${ }^{21)}$ are enhanced by nanoporous alumina. In contrast, titanium dioxide nanotubes with a diameter of $100 \mathrm{~nm}$ cause cell apoptosis, while nanotubes with 
a diameter of $15 \mathrm{~nm}$ enhance cell viability ${ }^{22)}$. An evaluation of NPG substrates in cell culture reported that they were safe and useful as drug delivery systems (DDS) ${ }^{23)}$; however, the data shown do not guarantee their safety in all cases. For example, NPG did not support microgrial growth, while flat gold (FG) did ${ }^{24)}$. Seker et al. ${ }^{25)}$ examined the activity of astrocytes cultured on NPG and showed that the cell coverage and cell area on NPG were lower than those on FG. It was recently reported that NPG had antibacterial activity against the bacteria Escherichia coli (E. coli) and Staphylococcus epidermidis while FG did not ${ }^{26,27)}$. The antibacterial activity of NPG was not a result of metal ions (silver and gold ions) or reactive oxygen species (ROS), both of which are often major factors in the antibacterial performance of nanomaterials ${ }^{28)}$. Transcriptomic analyses on the cultured E. coli suggested that NPG mainly disturbed the function of the cell membrane of E. coli, which governs the transport of various substances between the inner cytoplasm and the $\mathrm{ECM}^{26)}$. Hyperpolarization induced by NPG with large lattice strain plays an important role in the antibacterial activity of NPG, by causing the structure of

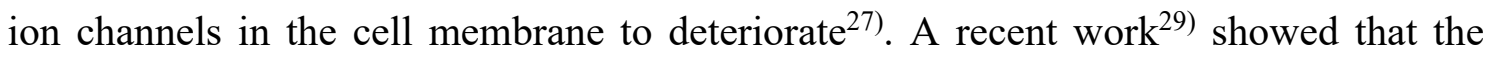
antibacterial activities of NPG have a positive correlation with their work functions because of the peculiar electronic states at the NPG surface. These studies suggest that NPG could have a specific influence on human cells. The effect of NPG on cultured cells 
must therefore be established in terms of fundamental science as well as in biomedical applications.

In the present work, the desorption and inactivation of HeLa cells adsorbed on NPG are investigated by measuring cells detached from the NPG substrate and apoptotic cells. In contrast to what is found for nanoparticles, cellular uptake of NPG does not occur because of its greater dimensions because the typical macroscopic lengths of NPG are greater than millimeters. Therefore, the ECM plays an important role in the interactions of NPG with cells because adherent cells such as HeLa adhere to a culture substrate via the ECM. Thus, we focus on the conformational change of ECM adsorbed on NPG with native polyacrylamide gel electrophoresis (native-PAGE) and enzyme-linked immuno sorbent (ELISA) analyses.

In addition, we investigate the conformational change of integrin, which regulates the outside-in signaling, with atomic simulations including first-principles calculations and molecular dynamics simulation. HeLa cells adhere to fibronectin, which is typical of ECM, using integrins ${ }^{30-32)}$, suggesting that NPG affects fibronectin and then the fibronectin has an effect on integrin. Therefore, two interactions, NPG/fibronectin and fibronectin/integrin, are investigated by the computational analyses. The adhesion motif of the RGD sequence plays a central role in the adhesion of fibronectin. It is important to 
investigate the electronic interactions of charge transfer or exchange-correlation interaction in the adsorption of polarized or charged amino acids such as Asp on a metallic substrate $^{33)}$. In particular, the peculiar electronic states at the NPG surface ${ }^{27,29)}$ must be considered to investigate the NPG/RGD interaction. Therefore, first-principles calculations are performed on the NPG/RGD interaction. It is accepted that binding of RGD to integrin induces a global conformational change of a hinge opening between the $\beta \mathrm{A}$ domain and the hybrid domain in the integrin headpiece ${ }^{34-37)}$. Molecular dynamics (MD) calculations are performed on the conformational change of the integrin headpiece caused by RGD interacting with NPG, to investigate the fibronectin/integrin interaction.

\section{Methods and materials}

\subsection{NPG and FG substrates}

In most experiments the NPG substrate was prepared by radio-frequency sputtering (SVC-700RF, Sanyu Electron, Japan) and subsequent dealloying on a 32-mm diameter glass dish, while other glass substrates were used for some experiments as explained later. First, supporting gold was sputtered onto the substrate using a pure gold ( $>99.9$ mass $\%$ ) target. For NPG, a supporting gold layer with thickness of $600 \mathrm{~nm}$ was sputtered to avoid delamination and fragmentation of the NPG during dealloying due to its brittleness and 
shrinkage ${ }^{38,39)}$. Then, $\mathrm{Au}_{0.3} \mathrm{Ag}_{0.7}$ alloy was sputtered onto the supporting gold layer to a thickness of $1000 \mathrm{~nm}$. After cooling the $\mathrm{Au}-\mathrm{Ag} / \mathrm{Au} / \mathrm{glass}$ dish at $253 \mathrm{~K}$ for $6 \mathrm{~h}$, NPG was synthesized by dealloying (free corrosion) at $253 \mathrm{~K}$ for $24 \mathrm{~h}$ in 69 mass $\% \mathrm{HNO}_{3}$, followed by thorough washing (10 or more times) with pure water to eliminate the residual $\mathrm{HNO}_{3}{ }^{40}$.

The surface structure of the fabricated NPG was observed using a scanning electron microscope (SEM, SU-6600, Hitachi High-Technologies, Japan). The quantitative chemical composition of the samples was analyzed with energy-dispersive X-ray spectroscopy (EDXS) equipped with SEM. For comparison, pure gold without nanoporous structure (300 $\mathrm{nm}$ in thickness) was sputtered onto the substrates to give FG. Cyclic voltammetry (CV) was carried out using a potentiostat (Automatic Polarization System, Hokuto Denko, Japan) for the determination of the electrochemically active surface area (ECSA) of the NPG and FG substrates. A typical three-electrode electrochemical cell with a Pt black counter electrode, a saturated calomel electrode (SCE) reference electrode, and the substrates $(\mathrm{NPG}$ and $\mathrm{FG})$ on cover glass $(18 \mathrm{~mm} \times 18$ mm, Matsunami Glass Industry, Japan) as the working electrodes, was used. CV was performed at $10 \mathrm{mV} / \mathrm{s}$ in a potential window of $-0.2 \mathrm{~V}$ to $+1.3 \mathrm{~V}$ (vs. SCE) at room temperature. We compared the surface area of each substrate by integrating the cathodic 
peak from +0.6 to $+1.05 \mathrm{~V}$, which coincides with the reduction of the oxidized monolayer formed on the gold surface during the anodic scan ${ }^{41)}$.

\subsection{Preparation of HeLa cells}

HeLa cells were purchased from RIKEN, Japan. Dulbecco's modified Eagle's medium (DMEM, Thermo Fisher Scientific, MA, USA) supplemented with 10\% heat inactivated fetal bovine serum (FBS, Thermo Fisher Scientific) and antibiotic-antimicotic (Thermo Fisher Scientific) was used for HeLa cell culture (in this paper, this supplemented medium is simply denoted DMEM unless otherwise stated).

HeLa cells were cultured under standard conditions at $310 \mathrm{~K}$ in an atmosphere of $5 \%$ $\mathrm{CO} 2$ in a relative humidity of $95 \pm 5 \%$. When the cells reached sub-confluence, they were harvested with TrypLETM Express (Thermo Fisher Scientific) and resuspended in $10 \mathrm{~mL}$ of DMEM. To remove TrypLETM Express, the suspension was centrifuged to give pellets of cells, and then $9 \mathrm{~mL}$ of the supernatant was removed. Fresh DMEM medium $(9 \mathrm{~mL})$ was then added and cells were dispersed by pipetting.

\subsection{Incubation of HeLa cells on substrates}


Approximately $3.5 \times 10^{5} \mathrm{HeLa}$ cells were seeded onto each substrate in $1.6 \mathrm{~mL}$ of DMEM. The dishes were then shaken horizontally to give a uniform cell density. HeLa cells on the substrates were observed after a certain incubation period at $310 \mathrm{~K}$ in an atmosphere of $5 \% \mathrm{CO}_{2}$. After detachment using TrypLETM Express, we calculated the adhesion rate $(=$ number of adherent cells / (number of desorbed cells + number of adherent cells)) of HeLa cells on each substrate using microscope observation. The numbers of dead and viable HeLa cells cultured on each substrate for $24 \mathrm{~h}$ were counted by mixing $10 \mu \mathrm{L}$ of the cell suspension and 0.4 mass $\%$ trypan blue aqueous solution (Thermo Fisher Scientific $)^{42,43)}$ and adding to a hemocytometer. The numbers were then used to give the inactivation rate $(=$ dead cell number / (viable cell number + dead cell number)).

\subsection{Apoptosis detection by fluorescence microscope observation}

Apoptosis detection was used to understand the mechanism of cell adhesion and inactivation. Apoptosis is the suicide or programmed cell death that maintains the condition of multicellular organisms ${ }^{44,45)}$. After culturing the HeLa cells for $24 \mathrm{~h}$, the substrates were washed 5 times with PBS to completely remove the floating cells so that 
only cells adhered to the substrates could be analyzed. Apoptosis reagent was then added dropwise to selectively stain apoptotic cells.

\subsection{Native polyacrylamide gel electrophoresis (PAGE) of culture media}

To establish the molecular weight composition of the culture media electrophoresis was carried out on DMEM medium after a 24-h incubation on each substrate. The supernatants were retrieved and mixed with NuPAGETM Sample Reducing Agent (Thermo Fisher Scientific) and NuPAGE LDS Sample Buffer (Thermo Fisher Scientific). The samples were then heated at $343 \mathrm{~K}$ for $10 \mathrm{~min}$. Finally, the samples were injected into a NuPAGE Bis-Tris gel (Thermo Fisher Scientific) and electrophoresed at $200 \mathrm{~V}$ constant voltage for 35 min. After electrophoresis, the gel was washed with deionized water three times and soaked in SimplyBlue SafeStain (Thermo Fisher Scientific) for $30 \mathrm{~min}$ to stain the proteins.

\subsection{ELISA analyses of active fibronectin adsorbed on substrates}

Fibronectin adsorbed on NPG and FG substrates was analyzed for determination of the fibronectin conformation. An x-well chamber (Sarstedt AG \& Co. KG, Germany) was used with the substrates for ELISA analysis. Glass slides were covered with FG or NPG 
as described in 2.1, and then the x-well chamber was attached to bear the liquid on the substrates and to ease handling of the samples to be analyzed.

The other ELISA analyses carried out using the protocol found in ref. 46, were conducted to reveal the conformation of fibronectin adsorbed on the NPG and FG substrates. First, fibronectin (human, plasma, Thermo Fisher Scientific) was dissolved in distilled water and the concentration was adjusted to $1 \mathrm{mg} / \mathrm{mL}$. It was then diluted to a concentration of 1,2 , or $4 \mu \mathrm{g} / \mathrm{mL}$ using PBS and added to NPG and FG substrates at 277 $\mathrm{K}$ for overnight immobilization. After the immobilization, the substrates were washed three times with PBS and blocked with bovine serum albumin. After washing three more times, the primary antibody (Fibronectin / Anastellin Antibody (HFN7.1) ${ }^{46-48)}$ (Novus Biologicals, CO, USA)) was added and the temperature was maintained at $310 \mathrm{~K}$ for 30 min. After washing five times with PBS, reactant was added and the samples were kept at room temperature for $15 \mathrm{~min}$. A reaction stop solution was then added and the fluorescence intensity at a wavelength of $450 \mathrm{~nm}$ was measured using an absorption plate reader.

\subsection{Statistical methods}


All experimental results were shown as the mean values with the corresponding standard deviations (SD).

\subsection{First-principles calculations of NPG/fibronectin interaction}

A gold (111) surface model, whose supercell consisted of 4 layers of $4 \sqrt{3} \times 3 \sqrt{3}$ gold atoms and $15 \AA$ vacuum gap, resulting in 144 gold atoms, was used as an FG model. Nanoporous metals have large lattice strains at the surface ${ }^{49-52)}$. Previous work ${ }^{27)}$ showed that the NPG surface was hyperpolarized by a 5\% compressive lattice strain, which led to the antimicrobial activity. Therefore, a gold (111) surface model with 5\% compressive lattice strain was used as the NPG model.

An RGD sequence was modeled from the X-ray crystal structure of fibronectin III 710 tetramer (PDB code: $1 \mathrm{FNF}^{53)}$ ). Hong et al. ${ }^{33)}$ showed that the binding energy of Asp with $\mathrm{Au}(111)$ was lower than that of Arg, indicating that the Asp side chains preferentially bind to the Au surface. They also showed that when oxygen atoms of the Asp side chain adsorbed on the atop site of the gold (111) surface, the adsorption energy was lower than for adsorption on any other site ${ }^{33)}$. Thus, RGD was initially placed in such a way that oxygen atoms of the Asp side chain were close to the atop sites at the gold (111) surface (Fig. S1). 
Geometry optimizations by first-principles calculations of density functional theory (DFT) were performed on the RGD-NPG(FG) models using the Dmol3 code ${ }^{54,55)}$. The generalized gradient approximation (GGA) with the Perdew-Wang 1991 (PW91) exchange-correlation function ${ }^{56)}$ was applied. The influences of van der Waals (vdW) correction on the dispersive, covalent, and ionic bonds were taken into account in the Ortmann-Bechstedt-Schmidt (OBS) ${ }^{57)}$ framework. The gold atoms in the bottom layer were fixed during the geometry optimizations. A double numerical basis-set including a polarization function (DNP) was used. A Fermi smearing of 0.005 hartree was adopted. The Brillouin zone of $2 \times 1 \times 1^{27,29)}$ was sampled by Monkhorst-Pack k-point mesh ${ }^{58)}$.

A variation in the torsion angle of RGD was measured to investigate the conformational change of RGD due to interactions with the gold surface, where a variation in the torsion angle of RGD was defined as the difference in the torsion angle of RGD before and after interaction with the gold surface. Also, the density of states (DOS) in oxygen and gold atoms related to the $\mathrm{RGD} / \mathrm{NPG}(\mathrm{FG})$ interaction was calculated before and after interaction with the gold surface. In addition, Mulliken Population analysis ${ }^{59)}$ was performed to investigate charge transfer between $\mathrm{Au}$ and $\mathrm{Pt}$ atoms.

\subsection{Molecular dynamics simulations of fibronectin/integrin interaction}


MD simulations were performed with GROMACS 5.1.2 software package ${ }^{60,61)}$, using the OPLS all-atom force field. The integrin-fibronectin complex was modeled with the crystal structure of the human fibronectin III 7-10 (PDB:1FNF $\left.{ }^{53)}\right)$ and the crystal structures of the closed $\alpha_{v} \beta_{3}$ integrin headpiece with RGD (PDB: $1 L 5 G^{62)}$ ). Both of the crystal structures were docked without serious steric clash by overlapping RGD contained in both of the crystal structures ${ }^{63-65)}$. The complex model was centered at least $1.0 \mathrm{~nm}$ from the $157 \AA \times 157 \AA \times 157 \AA$ box edge and solvated by the SPC/E water molecules model. $\mathrm{Na}^{+}$counter ions were added to neutralize the system. The conformation of RGD was fixed during all of the simulations. The system was energy-minimized using the steepest descent algorithm (500,000 steps), with a time step of 2.0 fs. After the minimization, the system was equilibrated for $100 \mathrm{ps}$ in the NVT ensemble, where the temperature reached $300 \mathrm{~K}$. Following the NVT equilibration, 100 ps NPT equilibration was performed, resulting in the pressure and temperature of the system being adjusted to $1.0 \times 10^{5} \mathrm{~Pa}$ and $300 \mathrm{~K}$, respectively. The LINCS algorithm ${ }^{66)}$ was employed to constrain bond lengths involving hydrogen atoms, allowing a 2 fs time step in the simulation. The long-range electrostatic interaction was calculated using the particle-mesh Ewald $\left(\mathrm{PME}^{67)}\right)$ method with a cutoff radius of $10 \AA$. The initial velocity of the atom was given by the Maxwell distribution at $300 \mathrm{~K}$. The temperature and pressure were controlled using 
a velocity rescale (V-rescale) thermostat ${ }^{68)}$ and Parrinello-Rahman barostat $^{69}$, respectively. After the equilibration, the production MD run was performed for $20 \mathrm{~ns}$. All systems remained stable during MD simulation, exhibiting a root mean square deviation (RMSD) for the backbone of less than $0.2 \mathrm{~nm}$. In the calculations, $\mathrm{Mn}^{2+}$ coordinated at the MIDAS site of the original $\alpha_{v} \beta_{3}$ integrin crystal structure was replaced with $\mathrm{Mg}^{2+}$ because $\mathrm{Mg}^{2+}$ is abundant under physiological conditions and regulates the activation of integrin $^{70)}$.

\subsection{Principal component analysis of integrin activation}

Local rearrangement around the ligand-binding pocket develops into long-range conformational changes such as $\beta \mathrm{A} /$ hybrid hinge opening in integrin activation ${ }^{34-37)}$. Principal component analysis (PCA) was performed to capture the structural transition in the long-range conformational change. The variance-covariance matrix was calculated for the coordinates of the backbone atoms derived from the trajectory of the MD simulation, and then diagonalized to output the principal component eigenvectors. All structures in the trajectory were projected onto the space spanned by the first and second principal component eigenvectors to visualize the distribution of the conformation. 
In addition, a variation in the T-junction as a function of time was investigated to analyze the dynamic behavior of the conformations around the ligand-binding pocket and the headpiece hinge region, where the T-junction is defined as a hydrophobic contact between residues at the middle of the $\alpha 1$ helix and the top of the $\beta 6$ strand $^{71)}$. The distance between Leu ${ }^{134}$ of the $\alpha 1$ helix and $\mathrm{Leu}^{333}$ of the $\beta 6$ strand is another important factor in integrin activation ${ }^{64)}$. Thus, the $\mathrm{Leu}^{134}-\mathrm{Leu}^{333}$ distance was investigated, where the distance was defined as that between the $\mathrm{C}_{\beta}$-atoms of $\mathrm{Leu}^{134}$ and $\mathrm{Leu}^{333}$.

\section{Results}

\subsection{Microstructure of NPG}

The SEM image and EDXS profile of the NPG substrate are shown in Figs 1A and 1B, respectively. A nanoporous structure with an average ligament and pore size of approximately $20 \mathrm{~nm}$ was observed in the NPG substrate. As shown in Fig. 1B, the residual silver content was very small, below 4 at.\%. Previous research excluded the possible effect of 4 at $\%$ silver remaining in NPG, confirming that silver did not result in any change in the adhesion rate of astrocytes and neurons on NPG compared with nonsilver containing substrates ${ }^{72)}$. HeLa cells are intrinsically highly resistant to harmful factors in their environment, including silver ions ${ }^{73)}$. Therefore, given that 4 at. $\%$ silver 
has no effect on astrocytes and neurons, the residual silver in the NPG substrates is not expected to have an effect on HeLa cells. An SEM image of the FG substrate showed a featureless polycrystalline structure with no nanoporous structure (data not shown). Therefore, the prepared NPG and FG are suitable substrates for examining the effect of nanoporous structure on HeLa cells cultured thereon.

CV curves for the evaluation of the ECSA of each substrate are shown in Figs 1C and 1D. The shapes of the curves are typical of gold electrodes ${ }^{41)}$, suggesting that the electrochemical response of the prepared NPG and FG are essentially the same as that of pure gold. As a result of the peak integration, the ECSA of the NPG substrate was found to be 107 times larger than that of FG. The surface area of the samples was increased by introducing nanoporous structure.

[Figure 1]

\subsection{Inactivation and adhesion rates on NPG and FG}

Figure 2A shows the inactivation rate of HeLa cells on NPG and FG substrates for 24 h. The average inactivation rates were $70 \%$ and $12 \%$ on the NPG and FG substrates, respectively (there is a statistically significant difference in the inactivation rates between 
the NPG and FG substrates with $p<0.05)$. This result indicates that more HeLa cells die on NPG than on FG, which is similar to a previous result where NPG was shown to kill bacteria $^{26}$.

Figure 2B shows the adhesion rate of HeLa cells cultured on NPG or FG substrates for 4, 10, 16, and $24 \mathrm{~h}$. Two important points arose: (1) More HeLa cells were desorbed for NPG than for FG. Based on the adhesion rate after culturing for $24 \mathrm{~h}$, there was a distinct difference in the adhesion rate of HeLa cells on NPG compared with FG. The adhesion rates were $16 \%$ and $89 \%$ on NPG and FG substrates, respectively (there was a statistically significant difference in the adhesion rates between NPG and FG substrates with $p<0.05$ ). This result indicates that HeLa cells cannot maintain adhesion to the NPG substrate, showing that NPG has an abnormal effect on the adhesion of HeLa cells, despite FG (bulk gold) being chemically and biologically inert. This result is consistent with the inactivation rate discussed above; both results show that HeLa cells are inactivated by NPG. (2) A certain period was required for desorption of the HeLa cells from the NPG substrate. After 4 and $10 \mathrm{~h}$ of HeLa cell culture, there was very little difference in the adhesion rates of HeLa Cells on NPG and FG substrates. This indicates that the inactivation of HeLa cells by NPG required a certain period (at least $10 \mathrm{~h}$ in this experiment). Indeed, HeLa cells were inactivated after they had adhered to the NPG 
substrate. The initial adhesion of the HeLa cells means that their inactivation by the NPG was not attributed to potentially harmful species diffusing through the media, but to the direct contact between the NPG substrate and HeLa cells.

As shown above, more HeLa cells died and desorbed in the case of the NPG substrate. In general, adherent cells in culture, such as HeLa cells, adhere to a substrate via the ECM because essential signals for growth and survival are provided between cells and extracellular environments. If the adherent cells are desorbed from the ECM or substrate, anoikis - programmed cell death-will occur due to the desorption. We investigated whether anoikis occurred in the HeLa cells cultured on NPG; that is, we examined whether HeLa cells died after desorption or were desorbed after death on NPG. Figure 2C shows cells adhered to the NPG substrate, and Fig. 2D shows the apoptotic cells (redstained cells) among the cells in Fig. 2C. Numerous apoptotic cells were observed on the NPG substrate. If the cells underwent apoptosis after desorption, red-stained cells (as in Fig. 2D) should not be observed because desorbed cells would already have been washed away with PBS before observation. In contrast, very few apoptotic cells were observed on the FG substrate (data not shown). These observations suggest that most of the HeLa cells desorbed after death on the NPG, although cell desorption before death should not 
be completely neglected. This finding, together with the slow detachment after initial adhesion of HeLa cells on NPG substrates, supports the conclusion that the cell death induced by NPG is not due to either anoikis or diffusion of harmful species.

[Figure 2]

\subsection{Fibronectin on NPG and FG}

Figure 3A shows the electrophoresis gels of DMEM incubated on NPG and FG substrates. As the DMEM with FBS contained proteins other than fibronectin, several bands for various proteins with inherent molecular weight were expressed. Overall, similar bands were detected for the DMEM on the NPG and FG substrates. This suggests that NPG showed no particular catalytic activity for the decomposition of molecules in the supernatant DMEM. The bands for dimeric fibronectin were found around the molecular weight of $450 \mathrm{kDa}$; however, there was no difference in intensity between the bands from DMEM incubated on the NPG and FG substrates. In addition, no band for the monomer $(225 \mathrm{kDa})$ was observed. These results suggest that fibronectins and other proteins in the DMEM supernatant were not decomposed by NPG. 
However, according to the results of ELISA analyses of active fibronectin adsorbed on NPG and FG (Fig. 3B), the conformation around the amino-acid sequence controlling adsorption in fibronectin was changed. The absorption at $450 \mathrm{~nm}$ (vertical axis in Fig. 3B) for fibronectin on NPG was lower than that on FG, suggesting that the RGD site in fibronectin — a minimum length critical peptide for cell adhesion —adsorbed on NPG was inactivated compared with that adsorbed on $\mathrm{FG}^{46)}$. Therefore, NPG affected cell adhesion by altering the conformation in fibronectin, which binds the cell and substrate.

[Figure 3]

\subsection{Interaction of RGD with nanoporous gold}

The experimental results suggested that the cell death was related to the conformational change of fibronectin induced by NPG. In the case of anoikis, the conformational change induces the detachment of cells from the substrate, followed by apoptosis. However, the cell death induced by NPG was not related to anoikis. The conformational alteration of proteins by NPG has been reported for enzymes, with enzymes immobilized on NPG having been shown to be more thermally stable than those immobilized on $\mathrm{FG}^{73-77)}$. However, in the present work, fibronectin in the supernatant DMEM was not decomposed 
by NPG, and the amounts of adsorbed fibronectin were similar on NPG and FG. Therefore, the conformational change in this work is quite different from that reported for enzymes. The adhesion motif of the RGD sequence plays a central role in cell adhesion via fibronectin. The experimental results showed that the conformational change of RGD was more greatly induced by NPG. Details of the conformational change of RGD were investigated using first-principles calculations. The results are shown in Fig. 4. The torsion angle consisting of oxygen atoms in the carboxyl group of Asp ${ }^{\text {RGD }}$, which directly contacted the NPG surface, was significantly varied by NPG (Fig. 4A). In addition, NPG greatly varied the torsion angles not only in Asp ${ }^{\mathrm{RGD}}$, but also in $\mathrm{Arg}^{\mathrm{RGD}}$ and Gly ${ }^{\mathrm{RGD}}$, which did not bind directly to the NPG surface, suggesting that the effect of NPG spread throughout the RGD sequence.

Nanoporous metals have unusual surface lattice strain due to the duality of the positive and negative curvature of the surface; which is not observed in nanoparticles ${ }^{49-52)}$. This lattice strain induces the positively-hyperpolarized surface of $\mathrm{NPG}^{27}$. The large conformational change of RGD induced by NPG is therefore suggested to arise from the strong interaction of the RGD with the hyperpolarized NPG surface. The density of states (DOS) of the oxygen atom in the carboxyl group of Asp ${ }^{\mathrm{RGD}}$ and the gold atom before and after the binding between RGD and the gold surface, are shown in Figs 4B and 4C. For 
NPG, binding resulted in a peak, as indicated by the arrow (Fig. 4B), while no peak was found for FG (Fig. 4C), indicating that covalent-like binding was generated between the oxygen atom and the gold atom for NPG owing to the sharing of an electron pair between the atoms. Besides, the charge transfer between the gold atom of Au surface and the oxygen atom in the carboxyl group of $\mathrm{Asp}^{\mathrm{RGD}}$ was investigated by the Mulliken Population analysis. The results are shown in Table 1. It can be seen from Table 1 that ionic binding between the gold and the oxygen atoms was enhanced by NPG. These suggest that HeLa cells adhered more strongly to the NPG substrate than to the FG substrate, which corresponds with the finding that HeLa cells adhered to the NPG substrate at the initial stage of cell culture. However, more HeLa cells desorbed from the NPG substrate than the FG substrate. Therefore, the desorption of HeLa cells from the NPG substrate is clearly not related to physical mechanisms, but to biological ones.

[Figure 4 and Table 1]

\subsection{Outside-in signaling via integrin}

A variety of signals are transmitted from extracellular environments to intracellular ones via integrin ${ }^{78)}$. The outside-in signaling via integrin regulates various cell behaviors 
such as cell survival, cell proliferation, cell motility, control of transcription, and cytoskeletal organization $^{79}$. There are three states of integrin that are closely related to the ligand binding through an allosteric mechanism ${ }^{34,62,79-83)}$ : the bent form with closed headpiece, which is generated when integrin does not interact with a ligand; the extended form with closed headpiece, which occurs when integrin interacts with a ligand with low affinity; and the extended form with open headpiece, which is generated when integrin interacts with a ligand with high affinity. The integrin signals can be transmitted in the open headpiece, but only minimally in the closed headpiece, despite the binding to a ligand. The headpiece states of integrins binding to the RGD on NPG and FG substrates were investigated by PCA. The headpiece state was significantly changed in the $5 \mathrm{~ns}$ calculation for the integrin binding to the RGD on FG, as shown by the arrows in Figs 5C and 5D. The same observation was made for the integrin binding to an intact $\mathrm{RGD}^{84)}$. It is therefore suggested that the headpiece was changed from the closed state to the open state by the binding to the RGD on FG. However, the same change was not observed for the integrin binding to the RGD on NPG (Figs 5A and 5B). This suggests that the change in the headpiece from the closed to the open state was not generated for the integrin binding to RGD on NPG because of the large RGD conformational change induced by NPG. 
Puklin-Faucher et al. ${ }^{64)}$ showed that the binding pocket and interdomain $\alpha \mathrm{A} / \mathrm{hybrid}$ domain hinge on the distal end of the $\alpha \mathrm{A}$ domain are allosterically linked via a T-junction between the middle of the $\alpha 1$ helix and the top of the $\alpha 7$ helix. Therefore, the T-junction induced by ligand binding and hinge opening regulates the headpiece state. The hinge angle of the T-junction was measured to investigate the headpiece change from the closed state to the open state. The results are shown in Fig. 6. The opening of the T-junction was generated in the $5 \mathrm{~ns}$ calculation for integrin binding to the RGD on FG (Figs 6C and 6D) as well as for integrin binding to the intact RGD (Figs 6E and 6F), which corresponds well to the PCA results. However, the opening of the T-junction was not generated for integrin binding to the RGD on NPG (Figs 6A and 6B). The $\mathrm{Leu}^{333}$-Leu ${ }^{134} \mathrm{C}$-atom distance is reduced as a result of the opening of the T-junction ${ }^{64)}$. A decrease in the Leu ${ }^{333}$ Leu ${ }^{134}$ distance was found for integrin binding to the RGD on FG (Fig. 7C), as well as for integrin binding to the intact RGD (Fig. 7E), but not for integrin binding to the RGD on NPG (Fig. 7A). These results suggest that the outside-in signals cannot be intracellularly transmitted via integrin binding to RGD on NPG because the extended form with open headpiece is not generated owing to the large conformational change of RGD.

[Figures 5 and 6] 


\section{Discussion}

Unlike for nanoparticles, the cellular uptake of nanostructures such as nanoporous materials and nanotubes cannot occur because of their bulky dimensions. Therefore, such nanostructures indirectly affect adherent cells via the ECM. Oh et al. ${ }^{85)}$ showed that cell adhesion increased but differentiation rate decreased with decreasing diameter in nanotubes. In contrast, Park et al. ${ }^{22)}$ showed that cell apoptosis was induced by nanotubes with a diameter of $100 \mathrm{~nm}$, while the cell viability was enhanced by nanotubes with a diameter of $15 \mathrm{~nm}$. The present work showed that NPG induced cell apoptosis that was not related to anoikis. Therefore, nanostructures have various effects on cells. There have been numerous studies to date on the effects of surface chemistry on cell behavior ${ }^{86-89)}$, which suggest that the conformational change of the ECM induced by the surface chemistry affects the cell behavior. In addition, Tang et al. ${ }^{90)}$ showed that surface potential regulated osteogenic differentiation via conformational change of the ECM. The present work suggested that the hyperpolarized surface due to the lattice disorder of NPG caused the conformational change of adsorbed fibronectin, which led to cell apoptosis. However, the various effects of the nanostructures on cells cannot be explained by denaturation or conformational change of the ECM alone. Changes in the ECM are intracellularly 
transmitted via integrin, which regulates various cell behaviors. The fact that the cell death by NPG was not due to anoikis, but apoptosis which was caused for cells adhering to the NPG substrate indicates that NPG led to dysfunction in intracellular signaling for cell viability via integrin. The present work suggested that the outside-in signals cannot be intracellularly transmitted via integrin binding to the RGD on NPG because the extended form with open headpiece is not generated, owing to the large conformational change of RGD. Therefore, the importance of integrin signaling should be pointed out for understanding the various effects of the nanostructures on cells. In the case of nanoporous alumina $^{19-21)}$, the cell viability and differentiation were enhanced. The difference in effects of nanostructures on cell behavior should be related to integrin signaling. Thus, integrin signaling is suggested to play a central role in regulating the various effects of the nanostructures.

In the computational analyses of the present work, the lattice strain was considered, but nanocurvatures and edges at the NPG surface were not considered because of the limited number of atoms which could be calculated by the first-principles calculations. Nanocurvatures and edges cause strains at the surface. Hence, effects of nanocurvatures and edges may be essentially the same as that of lattice strain obtained in the present work, 
although the strains caused by nanocurvatures and edges are complicated. Further research is needed about effects of nanocurvatures and edges.

It is well known that nanoparticles have a high capacity for inducing cell death ${ }^{91-100)}$. This ability of nanoparticles to induce cell dysfunction is mainly due to the emission of $\operatorname{ROS}^{91-97)}$. The signaling pathways of $\mathrm{JNK} / \mathrm{p} 53$ and $\mathrm{NF} \kappa \beta$, which are related to apoptosis, were found to be responsible for cell dysfunction induced by the emission of ROS in nanoparticles ${ }^{95-97)}$. In contrast, there are some reports of nanoparticles inducing cell dysfunction without the emission of $\operatorname{ROS}^{98-100)}$, where nanoparticles caused the denaturation of the ECM, for example via unfolding. Deng et al. ${ }^{98)}$ showed that cell

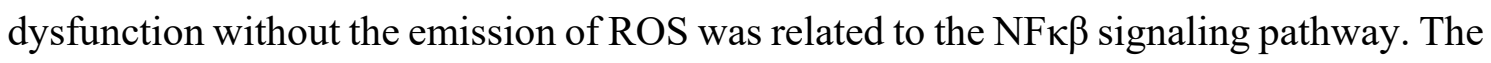
cell dysfunction induced by nanoparticles is therefore related to the same intracellular signaling regardless of whether ROS are emitted. Hence, the signaling is essential for the cell dysfunction induced by nanomaterials. The present work suggested that integrin signaling plays a central role in the cell death induced by NPG. Because the cellular uptake of nanoparticles occurs readily, nanoparticles directly affect the activation of intracellular signals regulating cell behaviors. However, cellular uptake of NPG cannot occur, therefore HeLa cells are required to adhere to the NPG substrate for a certain period 
(at least $10 \mathrm{~h}$ ) for the cell death by the integrin signaling, as demonstrated by the presented experimental results.

\section{Conclusion}

HeLa cells initially adhered to NPG over a period of more than $10 \mathrm{~h}$. Thereafter the adhered HeLa cells experienced apoptosis. The apoptosis was not related to anoikis because the cells died before desorption from the NPG substrate. ELISA analyses showed that the conformational change of fibronectin was more greatly induced by NPG, which corresponds to the first-principles calculation result. The molecular dynamics simulations suggested that the extended form of integrin with open headpiece was not generated owing to the large conformational change of fibronectin, therefore the outside-in signals could not be intracellularly transmitted via the integrin binding to the fibronectin on the NPG, which resulted in cell death.

\section{Acknowledgements}

This work was financially supported by the JSPS KAKENHI (Grant \#18H01734), which is acknowledged by M. M., and JSPS KAKENHI (Grant \#19H02458) and Sumitomo Foundation (Grant \#180400), which are acknowledged by M. H. 


\section{Appendix A. Supplementary data}

\section{REFERENCES}

[1] J. Biener, A. Wittstock, L.A. Zepeda-Ruiz, M.M. Biener, V. Zielasek, D. Kramer, R.N.

Viswanath, J. Weissmüller, M. Bäumer, A.V. Hamza, Surface-chemistry-driven actuation in nanoporous gold, Nat. Mater. 8 (2009) 47-51. https://doi.org/10.1038/nmat2335.

[2] D. Kramer, R.N. Viswanath, J. Weissmüller, Surface-stress induced macroscopic bending of nanoporous gold cantilevers, Nano Lett. 4 (2004) 793-796. https://doi.org/10.1021/n1049927d.

[3] H.J. Jin, X.L. Wang, S. Parida, K. Wang, M. Seo, J. Weissmüller, Nanoporous Au-Pt alloys as large strain electrochemical actuators, Nano Lett. 10 (2010) 187-194. https://doi.org/10.1021/n1903262b.

[4] S. Kameoka, A.P. Tsai, CO oxidation over a fine porous gold catalyst fabricated by selective leaching from an ordered AuCu3 intermetallic compound, Catal. Lett. 121 (2008) 337-341. https://doi.org/10.1007/s10562-007-9344-x.

[5] A. Wittstock, B. Neumann, A. Schaefer, K. Dumbuya, C. Kübel, M.M. Biener, V. Zielasek, H.P. Steinrück, J.M. Gottfried, J. Biener, A. Hamza, M. Bäumer, Nanoporous 
Au: an unsupported pure gold catalyst?, J. Phys. Chem. C 113 (2009) 5593-5600. https://doi.org/10.1021/jp808185v.

[6] V. Zielasek, B. Jürgens, C. Schulz, J. Biener, M.M. Biener, A.V. Hamza, M. Bäumer, Gold catalysts: nanoporous gold foams, Angew. Chem. Int. Ed. 45 (2006) 8241-8244. https://doi.org/10.1002/anie.200602484.

[7] C. Xu, J. Su, X. Xu, P. Liu, H. Zhao, F. Tian, Y. Ding, Low temperature CO oxidation over unsupported nanoporous gold, J. Am. Chem. Soc. 129 (2007) 42-43. https://doi.org/10.1021/ja0675503.

[8] A. Wittstock, A. Wichmann, J. Biener, M. Bäumer, Nanoporous gold: a new gold catalyst with tunable properties, Faraday Discuss. 152 (2011) 87-98. https://doi.org/10.1039/c1fd00022e.

[9] A. Wittstock, V. Zielasek, J. Biener, C.M. Friend, M. Bäumer, Nanoporous gold catalysts for selective gas-phase oxidative coupling of methanol at low temperature, Science 327 (2010) 319-322. https://doi.org/10.1126/science.1183591.

[10] M. Hakamada, F. Hirashima, M. Mabuchi, Catalytic decoloration of methyl orange solution by nanoporous metals, Catal. Sci. Technol. 2 (2012) 1814-1817. https://doi.org/10.1039/C2CY20218B. 
[11] L.Y. Chen, J.S. Yu, T. Fujita, M.W. Chen, Nanoporous copper with tunable nanoporosity for SERS applications, Adv. Funct. Mater. 19 (2009) 1221-1226. https://doi.org/10.1002/adfm.200801239.

[12] A.K. Mishra, C. Bansal, H. Hahn, Room temperature reversible tuning of magnetism of electrolyte-gated La0.75Sr0.25MnO3 nanoparticles, J. Appl. Phys. 103 (2008) 033913. https://doi.org/10.1063/1.4778918.

[13] T. Fujita, H. Okada, K. Koyama, K. Watanabe, S. Maekawa, M.W. Chen, Unusually small electrical resistance of three-dimensional nanoporous gold in external magnetic fields, Phys. Rev. Lett. $101 \quad$ (2008) 166601, https://doi.org/10.1103/PhysRevLett.101.166601.

[14] M.C. Dixon, T.A. Daniel, M. Hieda, D.M. Smilgies, M.H.W. Chan, D.L. Allara, Preparation, structure, and optical properties of nanoporous gold thin films, Langmuir 23 (2007) 2414-2422. https://doi.org/10.1021/la062313z.

[15] M. Hakamada, H. Nakano, T. Furukawa, M. Takahashi, M. Mabuchi, Hydrogen storage properties of nanoporous palladium fabricated by dealloying, J. Phys. Chem. C 114 (2010) 868-873. https://doi.org/10.1021/jp909479m.

[16] M. Hakamada, M. Takahashi, T. Furukawa, K. Tajima, K. Yoshimura, Y. Chino, M. Mabuchi, Electrochemical stability of self-assembled monolayers on nanoporous Au, 
Phys. Chem. Chem. Phys. $13 \quad$ (2011) 12277-12284. https://doi.org/10.1039/C0CP02553D.

[17] L. Richert, F. Variola, F. Rosei, J.D. Wuest, A. Nanci, Adsorption of proteins on nanoporous Ti surfaces, Surf. Sci. $604 \quad$ (2010) 1445-1451. https://doi.org/10.1016/j.susc.2010.05.007.

[18] T.J Webster, L.S. Schadler, R.W. Siegel, R. Bizios, Mechanisms of enhanced osteoblast adhesion on nanophase alumina involve vitronectin, Tissue Eng. 7 (2001) 291301. https://doi.org/10.1089/10763270152044152.

[19] S. Ni, C. Li, S. Ni, T. Chen, T.J. Webster, Understanding improved osteoblast behavior on select nanoporous anodic alumina, Int. J. Nanomedicine 9 (2014) 3325-3334. https://doi.org/10.2147/IJN.S60346.

[20] Y. Song, Y. Ju, Y. Morita, G. Song, Effect of the nanostructure of porous alumina on growth behavior of MG63 osteoblast-like cells, J. Biosci. Bioeng. 116 (2013) 509515. https://doi.org/10.1016/j.jbiosc.2013.04.007.

[21] Y. Song, Y. Ju, Y. Morita, In vitro proliferation and osteogenic differentiation of mesenchymal stem cells on nanoporous alumina, Int. J. Nanomedicine 8 (2013) 27452756. https://doi.org/10.2147/IJN.S44885. 
[22] J. Park, S. Bauer, K.V.D. Mark, P. Schmuki, Nanosize and vitality: TiO2 nanotube diameter directs cell fate, Nano Lett. $7 \quad$ (2007) 1686-1691. https://doi.org/10.1021/n1070678d.

[23] E. Şeker, W.C. Shih, K.J. Stine, Nanoporous metals by alloy corrosion: Bioanalytical and biomedical applications, MRS Bull. 43 (2018) 49-56. https://doi.org/10.1557/mrs.2017.298.

[24] Y.H. Tan, S.E. Terrill, G.S. Paranjape, K.J. Stine, M.R. Nichols, The influence of gold surface texture on microglia morphology and activation, Biomater. Sci. 2 (2014) 110-120. https://doi.org/10.1039/c3bm60096c.

[25] E. Seker, Y. Berdichevsky, K.J. Staley, M.L. Yarmush, Microfabrication-compatible nanoporous gold foams as biomaterials for drug delivery, Adv. Healthc. Mater. 1 (2012) 172-176. https://doi.org/10.1002/adhm.201200002.

[26] M. Hakamada, S. Taniguchi, M. Mabuchi, Antibacterial activity of nanoporous gold against Escherichia coli and Staphylococcus epidermidis, J. Mater. Res. 32 (2017) 17871795. https://doi.org/10.1557/jmr.2017.157.

[27] N. Miyazawa, M. Hakamada, M. Mabuchi, Antimicrobial mechanisms due to hyperpolarisation induced by nanoporous Au, Sci. Rep. 8 (2018) 3870, https://doi.org/10.1038/s41598-018-22261-5. 
[28] L. Wang, C. Hu, L. Shao, The antimicrobial activity of nanoparticles: present situation and prospects for the future, Int. J. Nanomedicine 12 (2017) 1227-1249. https://doi.org/10.2147/IJN.S121956.

[29] N. Miyazawa, S. Sakakibara, M. Hakamada, M. Mabuchi,. Electronic origin of antimicrobial activity owing to surface effect, Sci. Rep. 9 (2019) 1091. https://doi.org/10.1038/s41598-018-37645-w.

[30] M. Oba, S. Fukushima, N. Kanayama, K. Aoyagi, N. Nishiyama, H. Koyama, K. Kataoka, Cyclic RGD peptide-conjugated polyplex micelles as a targetable gene delivery system directed to cells possessing $\alpha v \beta 3$ and $\alpha v \beta 5$ integrins, Bioconjug. Chem. 18 (2007) 1415-1423. https://doi.org/10.1021/bc0700133.

[31] Y. Liu, F. Zhao, W. Gu, H. Yang, Q. Meng, Y. Zhang, H. Yang, Q. Duan, The roles of platelet GPIIb/IIIa and $\alpha v \beta 3$ integrins during HeLa cells adhesion, migration, and invasion to monolayer endothelium under static and dynamic shear flow, J. Biomed. Biotechnol. 2009 (2009) 829243, http://doi.org/10.1155/2009/829243.

[32] L. Xiong, M. Yu, M. Cheng, M. Zhang, X. Zhang, C. Xu, F. Li, A photostable fluorescent probe for targeted imaging of tumour cells possessing integrin $\alpha v \beta 3$, Mol. BioSyst. 5 (2009) 241-243. https://doi.org/10.1039/b820576k. 
[33] G. Hong, H. Heinz, R.R. Naik, B.L. Farmer, R. Pachter, Toward understanding amino acid adsorption at metallic interfaces: a density functional theory study, ACS Appl. Mater. Interfaces 1 (2009) 388-392. https://doi.org/10.1021/am800099z.

[34] J. Takagi, B.M. Petre, T. Walz, T.A. Springer, Global conformational rearrangements in integrin extracellular domains in outside-in and inside-out signaling, Cell 110 (2002) 599-611. http://doi.org/10.1016/S0092-8674(02)00935-2.

[35] B.H. Luo, K. Strokovich, T. Walz, T.A. Springer, J. Takagi, Allosteric $\beta 1$ integrin antibodies that stabilize the low affinity state by preventing the swing-out of the hybrid domain, J. Biol. Chem. $279 \quad$ (2004) 27466-27471. https://doi.org/10.1074/jbc.M404354200.

[36] B.H. Luo, T.A. Springer, J. Takagi, Stabilizing the open conformation of the integrin headpiece with a glycan wedge increases affinity for ligand, Proc. Natl. Acad. Sci. U.S.A. 100 (2003) 2403-2408. https://doi.org/10.1073/pnas.0438060100.

[37] A.P. Mould, S.J. Barton, J.A. Askari, P.A. McEwan, P.A. Buckley, S.E. Craig, M.J. Humphries, Conformational changes in the integrin $\beta$ A domain provide a mechanism for signal transduction via hybrid domain movement, J. Biol. Chem. 278 (2003) 1702817035. https://doi.org/10.1074/jbc.M213139200. 
[38] H.J. Jin, X.L. Wang, S. Parida, K. Wang, M. Seo, J. Weissmüller, Nanoporous Au-Pt alloys as large strain electrochemical actuators, Nano Lett. 10 (2010) 187-194. https://doi.org/10.1021/n1903262b.

[39] R. Li, K. Sieradzki, Ductile-brittle transition in random porous Au, Phys. Rev. Lett. 68 (1992) 1168-1171. https://doi.org/10.1103/PhysRevLett.68.1168.

[40] L.H. Qian, X.Q. Yan, T. Fujita, A. Inoue, M.W. Chen, Surface enhanced raman scattering of nanoporous gold: smaller pore sizes stronger enhancements, Appl. Phys. Lett. 90 (2007) 153120, https://doi.org/10.1063/1.2722199.

[41] S. Trasatti, O.A. Petrii, Real surface area measurements in electrochemistry, J. Electroanal. Chem. 327 (1992) 353-376. https://doi.org/10.1016/0022-0728(92)80162W.

[42] V. Dodane, M. Amin Khan, J.R. Merwin, Effect of chitosan on epithelial permeability and structure, Int. J. Pharm. 182 (1999) 21-32. https://doi.org/10.1016/S0378-5173(99)00030-7.

[43] S. Hagino, H. Itagaki, S. Kato, T. Kobayashi, M. Tanaka, Quantitative evaluation to predict the eye irritancy of chemicals: Modification of chorioallantoic membrane test by using trypan blue, Toxic. Vitro 5 (1991) 301-304. https://doi.org/10.1016/08872333(91)90006-Y. 
[44] J. Grossmann, Molecular mechanisms of "detachment-induced apoptosis - anoikis", Apoptosis 7 (2002) 247-260. https://doi.org/10.1023/A:1015312119693.

[45] J.F.R. Kerr, A.H. Wyllie, A.R. Currie, Apoptosis: A basic biological phenomenon with wide-ranging implications in tissue kinetics, Br. J. Cancer 26 (1972) 239-257. http://doi.org/10.1038/bjc.1972.33.

[46] A.J. García, M.D. Vega, D. Boettiger, Modulation of cell proliferation and differentiation through substrate-dependent changes in fibronectin conformation, Mol. Biol. Cell. 10 (1999) 785-798. http://doi.org/10.1091/mbc.10.3.785.

[47] P. François, P. Vaudaux, M. Taborelli, M. Tonetti, D.P. Lew, P. Descouts, Influence of surface treatments developed for oral implants on the physical and biological properties of titanium. (II) Adsorption isotherms and biological activity of immobilized fibronectin, Clin. Oral Implant. Res. 8 (1997) 217-225. https://doi.org/10.1034/j.16000501.1997.080308.x.

[48] M.C.V. Pessolani, P.J. Brennan, Mycobacterium leprae produces extracellular homologs of the antigen 85 complex, Infect. Immun. 60 (1992) 4452-4459.

[49] S. Parida, D. Kramer, C.A. Volkert, H. Rosner, J. Erlebacher, J. Weissmuller, Volume change during the formation of nanoporous gold by dealloying, Phys. Rev. Lett. 97 (2006), https://doi.org/10.1103/PhysRevLett.97.035504. 
[50] M. Hakamada, T. Furukawa, T. Yamamoto, M. Takahashi, M. Mabuchi, Abnormal hydrogen absorption/desorption properties of nanoporous Pt with large lattice strains, Mater. Trans. 52 (2011) 806-809. https://doi.org/10.2320/matertrans.M2010403.

[51] M. Hakamada, M. Yuasa, M. Mabuchi, Anomalous mechanical characteristics of $\mathrm{Au} / \mathrm{Cu}$ nanocomposite processed by $\mathrm{Cu}$ electroplating, Phil. Mag. 95 (2015) 1499-1510. https://doi.org/10.1080/14786435.2015.1038333.

[52] C. Mahr, K. Müller-Caspary, M. Graf, A. Lackmann, T. Grieb, M. Schowalter, F.F. Krause, T. Mehrtens, A. Wittstock, J. Weissmüller, A. Rosenauer, Measurement of local crystal lattice strain variations in dealloyed nanoporous gold, Mater. Res. Lett. 6 (2018) 84-92. https://doi.org/10.1080/21663831.2017.1396263.

[53] D.J. Leahy, I. Aukhil, H.P. Erickson, 2.0 A crystal structure of a four-domain segment of human fibronectin encompassing the RGD loop and synergy region, Cell 84 (1996) 155-164. https://doi.org/10.1016/S0092-8674(00)81002-8.

[54] B. Delley, An all-electron numerical method for solving the local density functional for polyatomic molecules, J. Chem. Phys. 92 (1990) 508-517. https://doi.org/10.1063/1.458452.

[55] B. Delley, From molecules to solids with the Dmol3 approach, J. Chem. Phys. 113 (2000) 7756-7764. https://doi.org/10.1063/1.458452. 
[56] Y. Wang, J.P. Perdew, Atoms, molecules, solids, and surfaces: Application of the generalized approximation for exchange and correlation, Phys. Rev. B 46 (1992) 66716687. https://doi.org/10.1103/PhysRevB.46.6671.

[57] F. Ortmann, F. Bechstedt, W.G. Schmidt, Semiempirical van der Walls correction to the density functional description of solids and molecular structures, Phys. Rev. B 73 (2006) 205101. https://doi.org/10.1103/PhysRevB.73.205101.

[58] H.J. Monkhorst, J.D. Pack, Special points for brillouin-zone integrations, Phys. Rev. B 13 (1976) 5188-5192. https://doi.org/10.1103/PhysRevB.13.5188.

[59] R.S. Mulliken, Electronic population analysis on LCAO-MO molecular wave functions. I, J. Chem. Phys. 23 (1955) 1833-1840. https://doi.org/10.1063/1.1740588.

[60] D.V.D. Spoel, E. Lindahl, B. Hess, G. Groenhof, A.E. Mark, H.J.C. Berendsen, GROMACS: fast, flexible, and free, J. Comput. Chem. 26 (2005) 1701-1718, https://doi.org/10.1002/jcc.20291.

[61] M.J. Abraham, T. Murtola, R. Schulz, S. Pall, J.C. Smith, B. Hess, E. Lindahl, GROMACS: high performance molecular simulations through multi-level parallelism from laptops to supercomputers, SoftwareX 1-2 (2015) 19-25. https://doi.org/10.1016/j.softx.2015.06.001. 
[62] J.P. Xiong, T. Stehle, R. Zhang, A. Joachimiak, M. Frech, S.L. Goodman, M.A. Arnaout, Crystal structure of the extracellular segment of integrin $\alpha \mathrm{V} \beta 3$ in complex with an Arg-Gly-Asp ligand, Science $296 \quad$ (2002) 151-155. https://doi.org/10.1126/science.1069040.

[63] E.P. Faucher, M. Gao, K. Schulten, V. Vogel, How the headpiece hinge angle is opened: new insights into the dynamics of integrin activation, J. Cell. Biol. 175 (2006) 349-360. http://doi.org/10.1083/jcb.200602071.

[64] E.P. Faucher, V. Vogel, Integrin Activation dynamics between the RGD-binding site and the headpiece hinge, J. Biol. Chem. 284 (2009) 36557-36568. http://doi.org/10.1074/jbc.M109.041194.

[65] V. Copie, Y. Tomita, S.K. Akiyama, S. Aota, K.M. Yamada, R.M. Venable, R.W. Pastor, S. Krueger, D.A. Torchia, Solution structure and dynamics of linked cell attachment modules of mouse fibronectin containing the RGD and synergy regions: comparison with the human fibronectin crystal structure, J. Mol. Biol. 277 (1998) 663682. https://doi.org/10.1006/jmbi.1998.1616.

[66] K.A. Feenstra, B. Hess, H.J.C. Berendsen, Improving efficiency of large time-scale molecular dynamics simulations of hydrogen-rich systems, J. Comp. Chem. 20 (1999) 
786-798.

https://doi.org/10.1002/(SICI)1096-987X(199906)20:8<786::AID-

$\mathrm{JCC} 5>3.0 . \mathrm{CO} ; 2-\mathrm{B}$.

[67] T. Darden, D. York, L. Pedersen, Particle mesh ewald: an N· $\log (\mathrm{N})$ method for ewald sums in large systems, J. Chem. Phys. 98 (1993) 10089. https://doi.org/10.1063/1.464397. [68] G. Bussi, D. Donadio, M. Parrinello, Canonical sampling through velocity rescaling, J. Chem. Phys. 126 (2007) 014101, https://doi.org/10.1063/1.2408420.

[69] M. Parrinello, A. Rahman, Polymorphic transitions in single crystals: a new molecular dynamics method, J. Appl. Phys. 52 (1981) 7182-7190. https://doi.org/10.1063/1.328693.

[70] A.P. Mould, S.K. Akiyama, M.J. Humphries, Regulation of integrin $\alpha 5 \beta 1-$ fibronectin interactions by divalent cations, J. Biol. Chem. 270 (1995) 26270-26277. https://doi.org/10.1074/jbc.270.44.26270.

[71] T. Xiao, J. Takagi, J.H. Wang, T.A. Springer, Structural basis for allostery in integrins and binding to fibrinogen-mimetic therapeutics, Nature 432 (2004) 59-67. https://doi.org/10.1038/nature02976.

[72] C.A.R. Chapman, H. Chen, M. Stamou, J. Biener, M.M. Biener, P.J. Lein, E. Seker, Nanoporous gold as a neural interface coating: effects of topography, surface chemistry, and feature size, ACS Pub. 7 (2015) 7093-7100. https://doi.org/10.1021/acsami.5b00410. 
[73] S.I. Kaba, E.M. Egorova, In vitro studies of the toxic effects of silver nanoparticles on HeLa and U937 cells, Nanotechnol. Sci. Appl. 8 (2015) 19-29. https://doi.org/10.2147/NSA.S78134.

[74] M. Hakamada, M. Takahashi, M. Mabuchi, Enhanced thermal stability of laccase immobilized on monolayer-modified nanoporous Au, Mater. Lett. 66 (2011) 4-6. https://doi.org/10.1016/j.matlet.2011.08.017.

[75] H. Qiu, C. Xu, X. Huang, Y. Ding, Y. Qu, P. Gao, Adsorption of laccase on the surface of nanoporous gold and the direct electron transfer between them, J. Phys. Chem. C 112 (2008) 14781-14785. https://doi.org/10.1021/jp805600k.

[76] H. Qiu, C. Xu, X. Huang, Y. Ding, Y. Qu, P. Gao, Immobilization of laccase on nanoporous gold: comparative studies on the immobilization strategies and the particle size effects, J. Phys. Chem. C 113 (2009) 2521-2525. https://doi.org/10.1021/jp8090304. [77] M. Hakamada, M. Takahashi, M. Mabuchi, Enzyme electrodes stabilized by monolayer-modified nanoporous $\mathrm{Au}$ for biofuel cells, Gold Bull. 45 (2012) 9-15. https://doi.org/10.1007/s13404-011-0038-1.

[78] F.G. Glancotti, E. Ruoslahti, Integrin signaling, Science 285 (1999) 1028-1032. https://doi.org/10.1126/science.285.5430.1028. 
[79] R.O. Hynes, Integrins: bidirectional, allosteric signaling machines, Cell 110 (2002)

673-687. https://doi.org/10.1016/S0092-8674(02)00971-6.

[80] J. Emsley, C.G. Knight, R.W. Farndale, M.J. Barnes, R.C. Liddington, Structural basis of collagen recognition by integrin $\alpha 2 \beta 1$, Cell 101 (2000) 47-56. https://doi.org/10.1016/S0092-8674(00)80622-4.

[81] B.H. Luo, T.A. Springer, Integrin structures and conformational signaling, Curr.

Opin. Cell Biol. 18 (2006) 579-586. https://doi.org/10.1016/j.ceb.2006.08.005.

[82] B.H. Luo, C.V. Carman, T.A. Springer, Structural basis of integrin regulation and signaling, Annu. Rev. Immunol. $25 \quad$ (2007) 619-647. https://doi.org/10.1146/annurev.immunol.25.022106.141618.

[83] J. Zhu, J. Zhu, T.A. Springer, Complete integrin headpiece opening in eight steps, J. Cell Biol. 201 (2013) 1053-1068. http://doi.org/10.1083/jcb.201212037.

[84] A. Paladino, M. Civera, L. Belvisi, G. Colombo, High affinity vs. native fibronectin in the modulation of $\alpha v \beta 3$ integrin conformational dynamics: insights from computational analyses and implications for molecular design, PLoS Comput. Biol. 13 (2017) e1005334, http://doi.org/ 10.1371/journal.pcbi.1005334. 
[85] S. Oh, K.S. Brammer, Y.S.J. Li, D. Teng, A.J. Engler, S. Chien, S. Jin, Stem cell fte dictated solely by altered nanotube dimension, Proc. Natl. Acad. Sci. U.S.A. 106 (2009) 2130-2135. https://doi.org/10.1073/pnas.0813200106.

[86] C.C. Barrias, M.C.L. Martins, G. Almeida-Porada, M.A. Barbosa, P.L. Granja, The correlation between the adsorption of adhesive proteins and cell behaviour on hydroxylmethyl mixed self-assembled monolayers, Biomaterials 30 (2009) 307-316. https://doi.org/10.1016/j.biomaterials.2008.09.048.

[87] B.G. Keselowsky, D.M. Collard, A.J. Garcia, Surface chemistry modulates focal adhesion composition and signaling through changes in integrin binding, Biomaterials 25 (2004) 5947-5954. https://doi.org/10.1016/j.biomaterials.2004.01.062.

[88] M. Lin, H. Wang, C. Ruan, J. Xing, Y. Li, Y. Wang, Y. Luo, Adsorption force of fibronectin on various surface chemistries and its vital role in osteoblast adhesion, Biomacromolecules 16 (2015) 973-984. https://doi.org/10.1021/bm501873g.

[89] K.E. Michael, V.N. Vernekar, B.G. Keselowsky, J.C. Meredith, R.A. Latour, A.J. Garcia, Adsorption-induced conformational changes in fibronectin due to interactions with well-defined surface chemistries, Langmuir 19 (2003) 8033-8040. https://doi.org/10.1021/la034810a. 
[90] B. Tang, B. Zhuang, Q. Wang, L. Dong, K. Cheng, W. Weng, Surface potentialgoverned cellular osteogenic differentiation on ferroelectric polyvinylidene fluoride trifluoroethylene films, Acta. Biomater. 74 (2018) 291-301. https://doi.org/10.1016/j.actbio.2018.04.051.

[91] A.M. Alkilany, C.J. Murphy, Toxicity and cellular uptake of gold nanoparticles: what we have learned so far?, J. Nanopart. Res. 12 (2010) 2313-2333. https://doi.org/10.1007/s11051-010-9911-8.

[92] D. Septiadi, F. Crippa, T.L. Moore, B. Rothen-Rutishauser, A. Petri-fink, A., 2018. Nanoparticle-cell interaction: a cell mechanics perspective. Adv. Mater. 30, e1704463. https://doi.org/10.1002/adma.201704463.

[93] C. Carlson, S.M. Hussain, A.M. Schrand, L.K. Braydich-Stolle, K.L. Hess, R.L. Jones, J.J. Schlager, Unique cellular interaction of silver nanoparticles: size-dependent generation of reactive oxygen species, J. Phys. Chem. B 112 (2008) 13608-13619. https://doi.org/10.1021/jp712087m.

[94] Y. Pan, A. Leifert, D. Ruan, S. Neuss, J. Bornemann, G. Brandau, U. Simon, W. Jahnen-Dechent, Gold nanoparticles of diameter $1.4 \mathrm{~nm}$ trigger necrosis by oxidative stress and mitochondrial damage, Small $5 \quad$ (2009) 2067-2076. https://doi.org/10.1002/smll.200900466. 
[95] X. Liu, J. Sun, Endothelial cells dysfunction induced by silica nanoparticles through oxidative stress via JNK/P53 and NF-кB pathways, Biomaterials 31 (2010) 8198-8209. https://doi.org/10.1016/j.biomaterials.2010.07.069.

[96] M.I. Setyawati, C.Y. Tay, D.T. Leong, Effect of zinc oxide nanomaterials-induced oxidative stress on the p53 pathway, Biomaterials 34 (2013) 10133-42. https://doi.org/10.1016/j.biomaterials.2013.09.024.

[97] S.F. Ye, Y.H. Wu, Z.Q. Hou, Q.Q. Zhang, ROS and NF-kB are involved in upregulation of IL-8 in A549 cells exposed to multi-walled carbon nanotubes, Biochem. Biophys. Res. Commun. 379 (2009) 643-648. https://doi.org/10.1016/j.bbrc.2008.12.137. [98] Z.J. Deng, M. Liang, M. Monteiro, I. Toth, R.F. Minchin, Nanoparticle-induced unfolding of fibrinogen promotes Mac-1 receptor activation and inflammation, Nature Nanotechnology 6 (2011) 39-44. https://doi.org/10.1038/nnano.2010.250.

[99] S.J. Soenen, N. Nuytten, S.F. De Meyer, S.C. De Smedt, M. De Cuyper, High intracellular iron oxide nanoparticle concentrations affect cellular cytoskeleton and focal adhesion kinase-mediated signaling, Small $6 \quad$ (2010) 832-842. https://doi.org/10.1002/smll.200902084.

[100] K.O. Yu, C.M. Grabinski, A.M. Schrand, R.C. Murdock, W. Wang, B. Gu, J.J. Schlager, S.M. Hussain, Toxicity of amorphous silica nanoparticles in mouse 
keratinocytes, J. Nanoparticle Res. 11 (2009) 15-24. https://doi.org/10.1007/s11051-008-

9417-9. 


\section{Tables}

Table 1. Variations in charge of gold atom of Au surface and oxygen atom in carboxyl group of Asp ${ }^{R G D}$ by binding of Asp ${ }^{R G D}$ with Au surface for flat Au and nanoporous Au. The positive/negative value of charge variation means that the charge is decreased/increased.

\begin{tabular}{ccc}
\hline Substrate & Binding Atom & Charge variation \\
\hline flat $\mathrm{Au}$ & oxygen & -0.017 \\
& gold & +0.040 \\
\hline nanoporous $\mathrm{Au}$ & oxygen & -0.070 \\
& gold & +0.168 \\
\hline
\end{tabular}




\section{List of Figures}

A

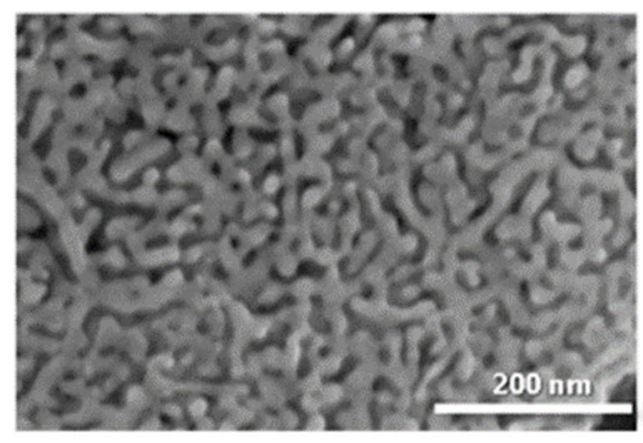

C

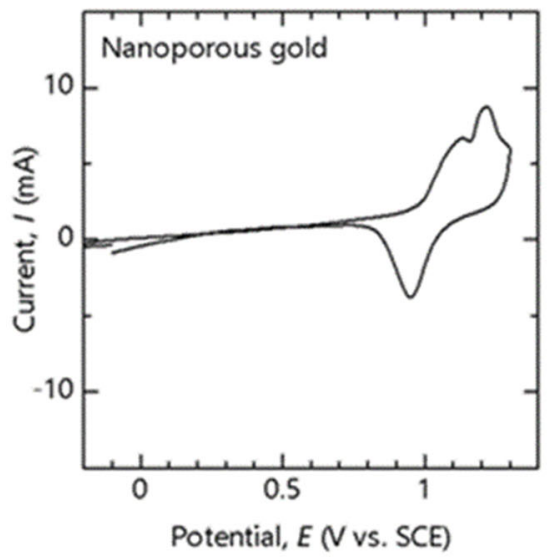

B

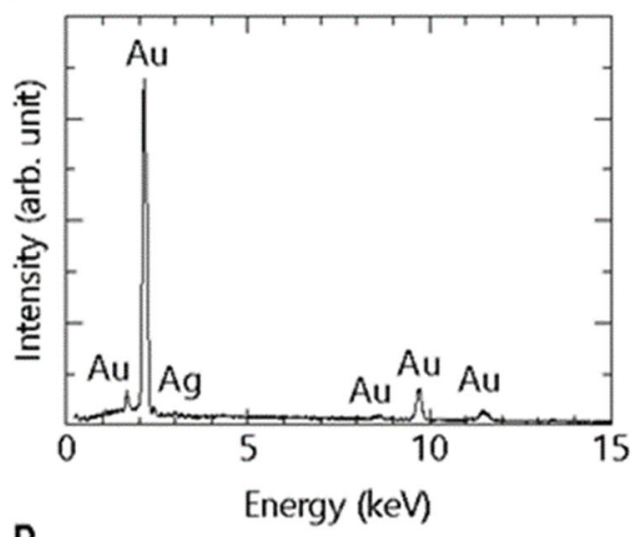

D

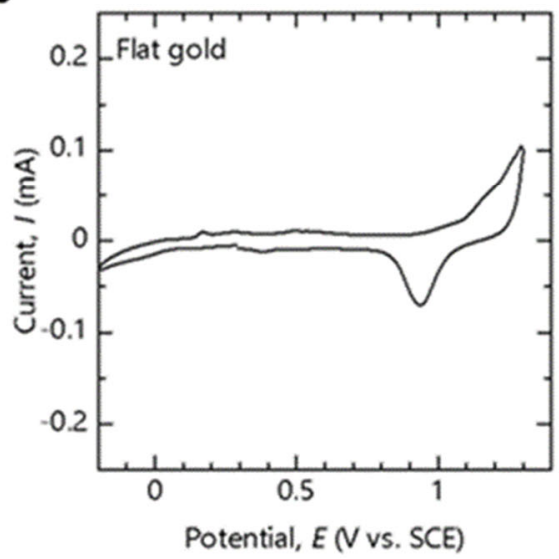

Figure 1. Characterization of nanoporous gold (NPG). (A) SEM image of NPG. Ligaments and pores with an average diameter of $20 \mathrm{~nm}$ were three-dimensionally connected. (B) Energy-dispersive X-ray spectrum for NPG. Mainly gold was detected, with very little silver, suggesting that the silver was sufficiently removed during dealloying in $\mathrm{HNO}_{3}$. (C) Cyclic voltammetry curve for NPG. (D) Cyclic voltammetry of flat gold (FG). (C) and (D) suggest that the electrochemical surface properties of NPG and FG were essentially the same, although the electrochemically-active surface area was much higher for NPG than for FG. 

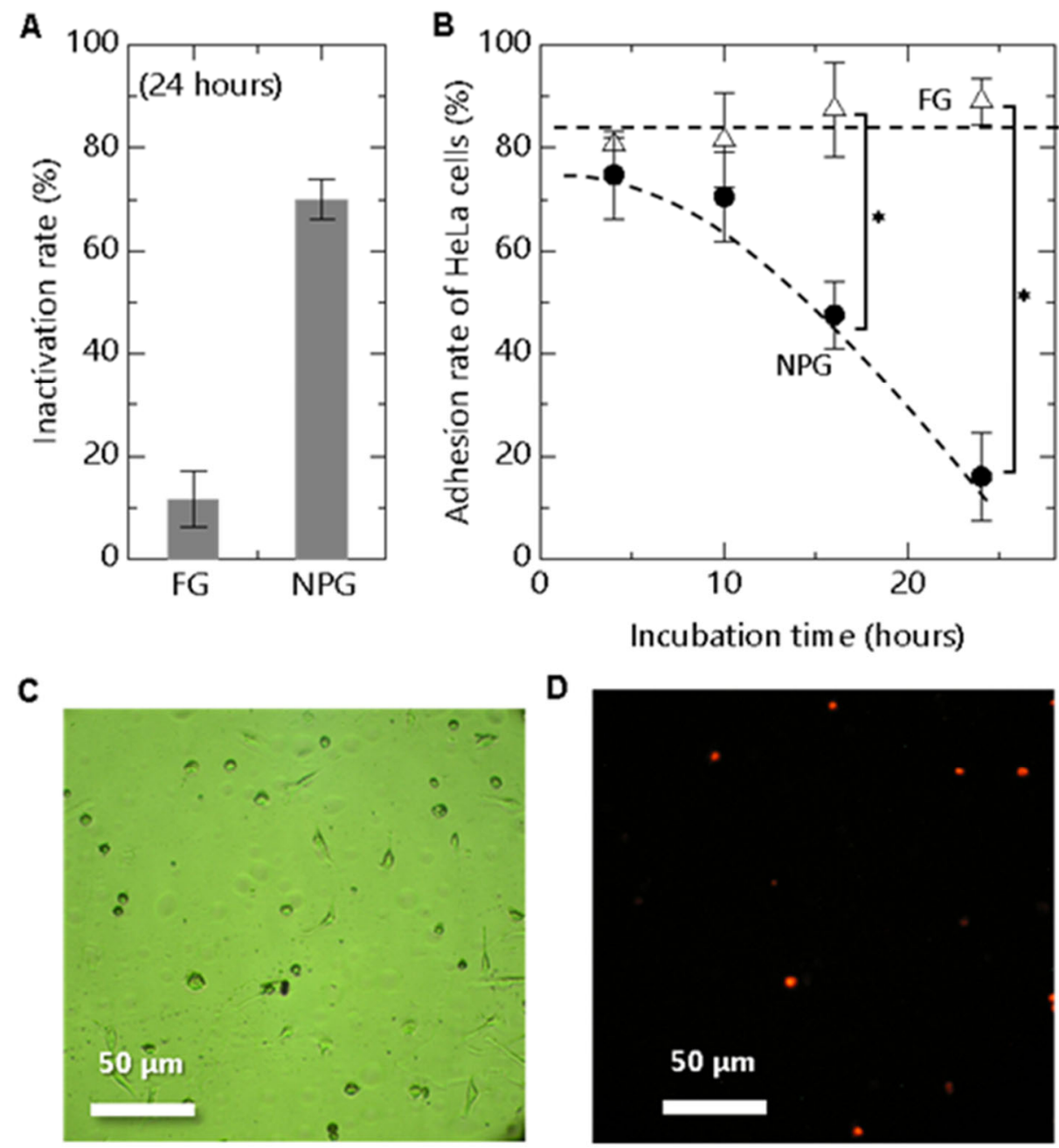

Figure 2. Comparison of HeLa cells cultured on nanoporous gold (NPG) and flat gold (FG) substrates. (A) Inactivation rate of HeLa cells on NPG and FG substrates, showing a higher inactivation rate for NPG substrates (there is a statistically significant difference in the inactivation rates between NPG and FG substrates with $p<0.05$ ). (B) Time variation for adhesion rate of HeLa cells cultured on NPG and FG substrates. After a 10h culture, HeLa cells detached from the NPG substrate, but remained adhered to the FG substrate. Asterisks denote a statistically significant difference in the inactivation rates between the NPG and FG substrates with $p<0.05$. (C) Bright-field and (D) fluorescence microscope observation images of HeLa cells cultured on NPG for $24 \mathrm{~h}$. In image (D) apoptotic cells are stained red. 
A

\section{B}

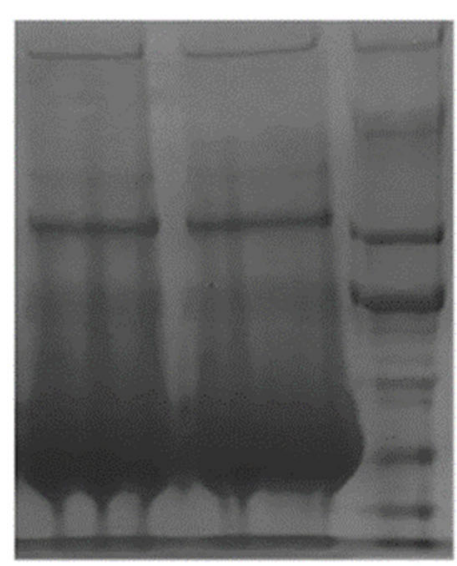

$460 \mathrm{kDa}$

FG

NPG Molecular

weight

marker

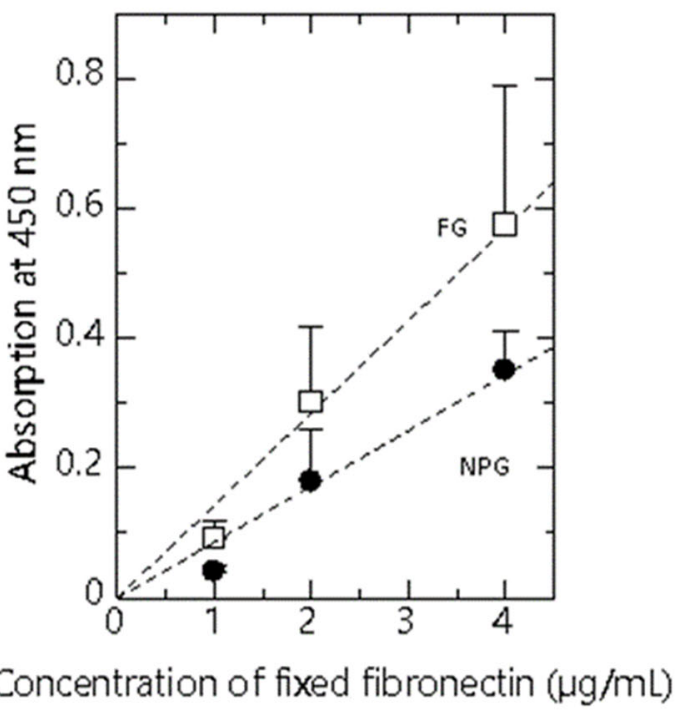

Figure 3. Analyses of proteins including fibronectin. (A) Electrophoresis gel after nativePAGE. No difference in the protein composition was detected between the nanoporous gold (NPG) and flat gold (FG) substrates. (B) Relationship between fluorescence intensity and concentration of fixed active fibronectin quantified according to the protocol in ref. 46. The intensity was lower in NPG than in FG, suggesting a conformational change in amino-acid motifs related to the adhesion of cells. 


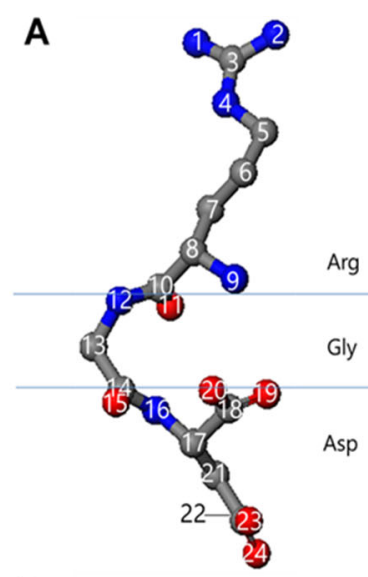

B
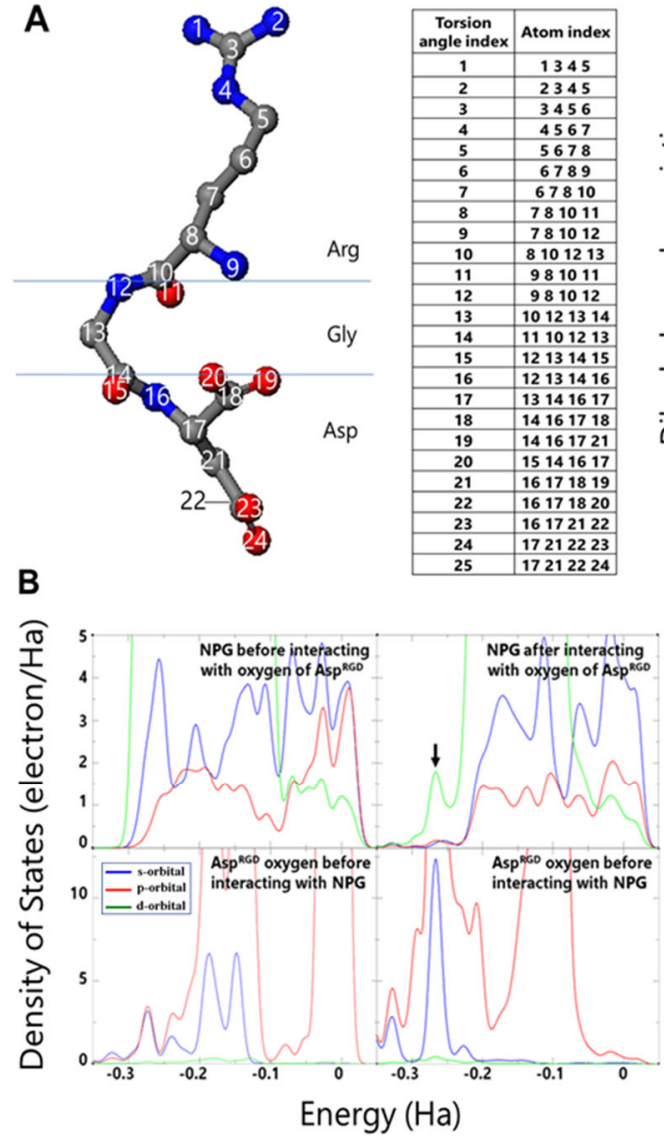

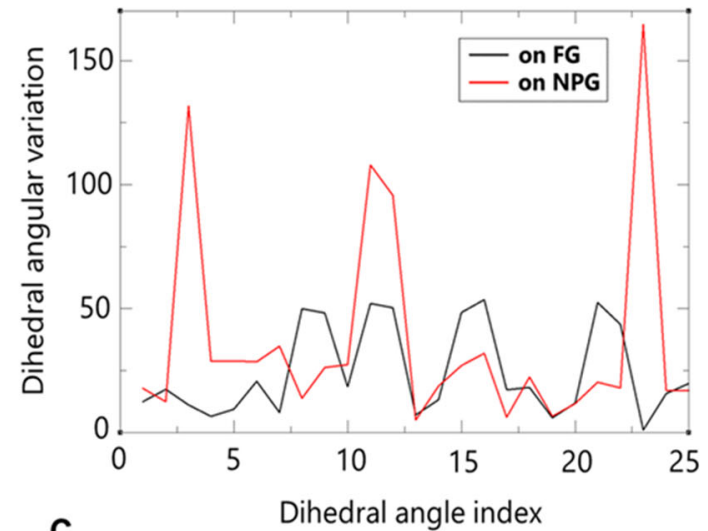

C

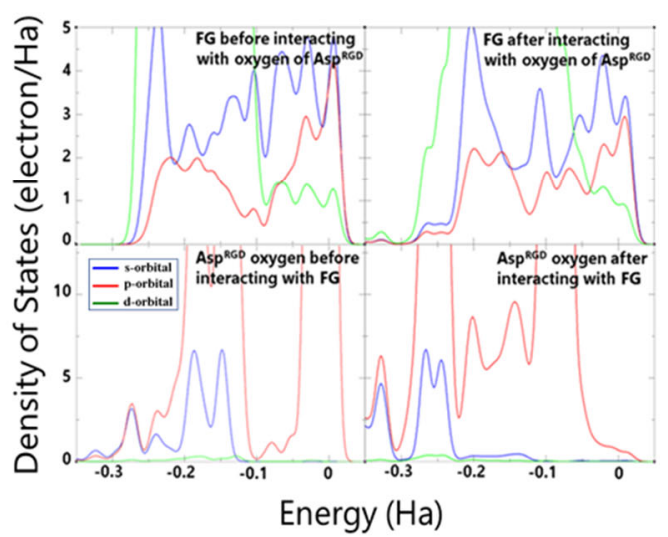

Figure 4. Results of first-principles calculations of the conformational change of the RGD sequence. (A) Variation in torsion angle of RGD before and after binding to nanoporous gold (NPG) or flat gold (FG) substrates. The red, gray, and blue spheres indicate oxygen, carbon, and nitrogen atoms, respectively. The torsion angle is calculated from the positions of the four atoms. NPG significantly varied the torsion angles not only in Asp ${ }^{R G D}$, but also in $\operatorname{Arg}^{R G D}$ and Gly ${ }^{R G D}$. (B and C) Density of states (DOS) of the oxygen atom in the carboxyl group of $\mathrm{Asp}^{\mathrm{RGD}}$ and the gold atom before and after binding between the RGD and gold surface for NPG (B) and FG (C). The blue, red and yellow lines indicate partial density of states in s, p and d orbits, respectively. A peak that indicates covalent-like binding between the oxygen atom and gold atom was found for NPG, as indicated by the arrow. 
A

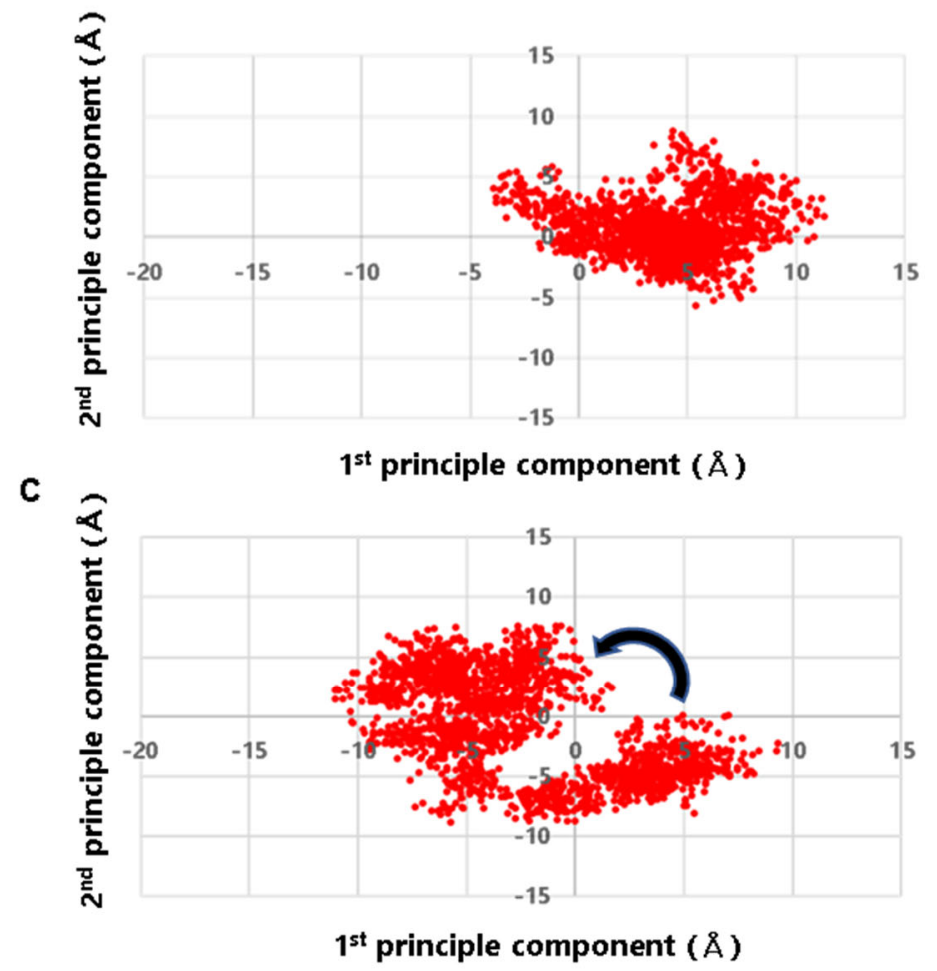

B
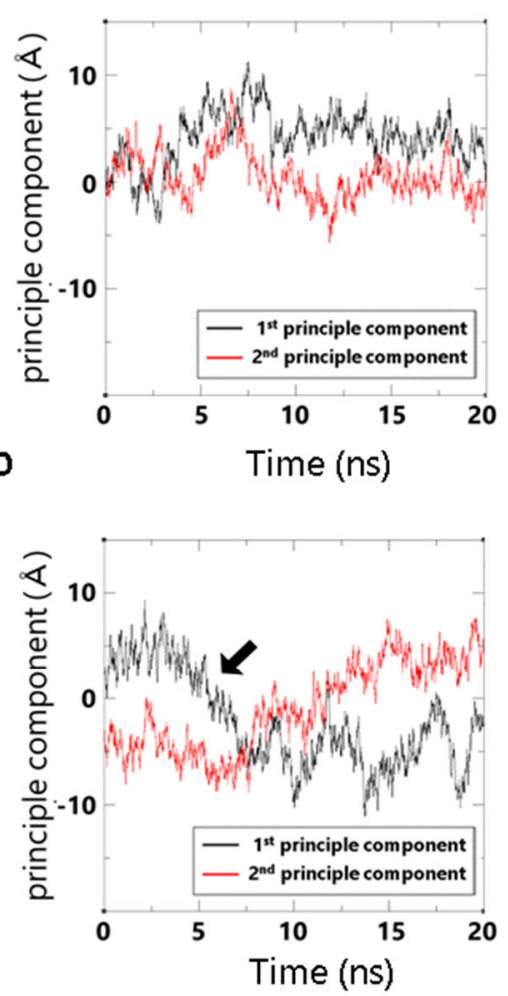

Figure 5. Principal component analyses of $\alpha v \beta 3$ integrin headpiece binding to the RGD sequence. (A) Projections of the conformation of the integrin headpiece onto the space spanned by two principal vectors derived from the trajectory of molecular motions in interacting with RGD on nanoporous gold (NPG). (B) Variation in the conformation of the integrin headpiece through interaction with RGD on NPG as a function of time, where the molecular motions of integrin are projected to the first and second principal component vectors. (C) Projections of the conformation of the integrin headpiece interacting with RGD on flat gold (FG). (D) Variation in the conformation of the integrin headpiece through interacting with RGD on FG. In (A) and (C), the vertical and horizontal axes represent the deviation along the first and second principal vectors from the initial structure of integrin in angstrom order, respectively. The headpiece state was significantly changed in the 5 ns calculation for the integrin binding to RGD on FG, as shown by the arrows in (C) and (D), however, a comparable change was not found for the integrin binding to RGD on NPG. 


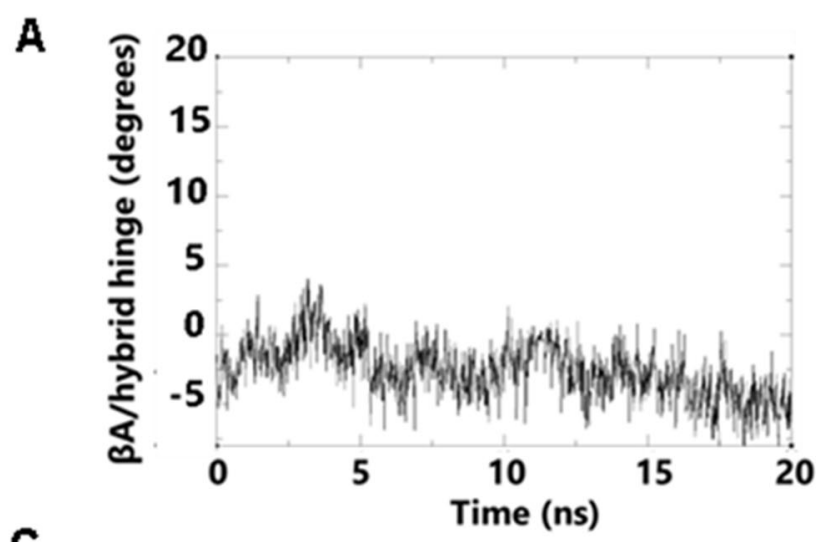

C

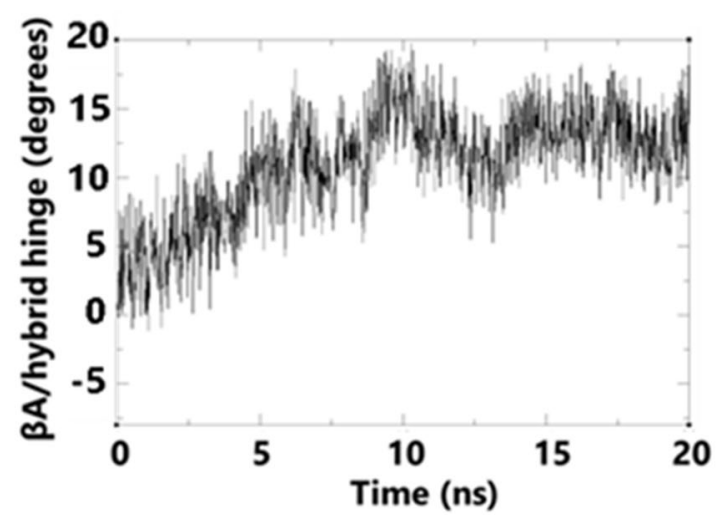

E

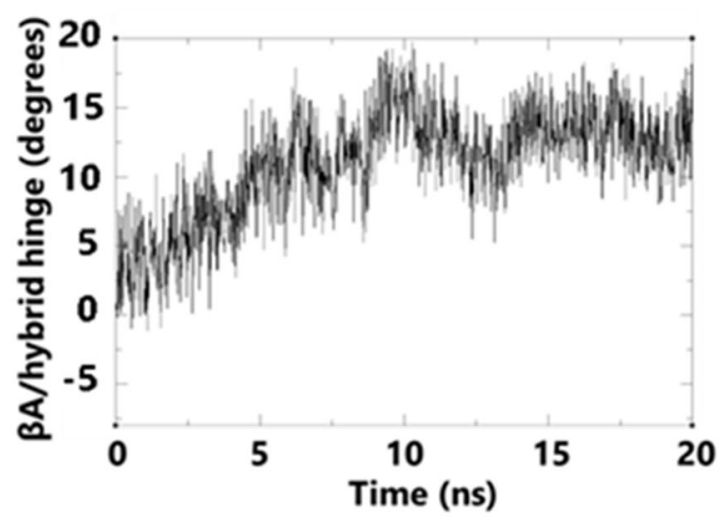

B

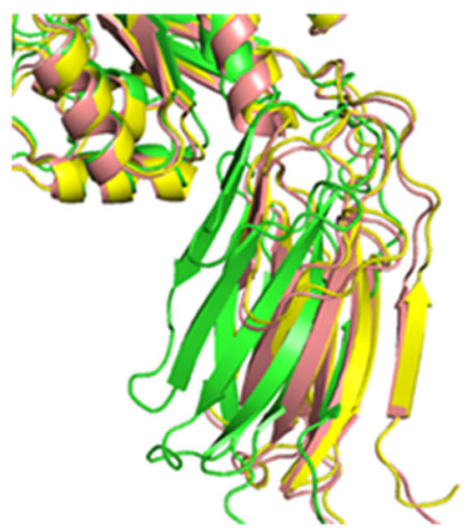

D

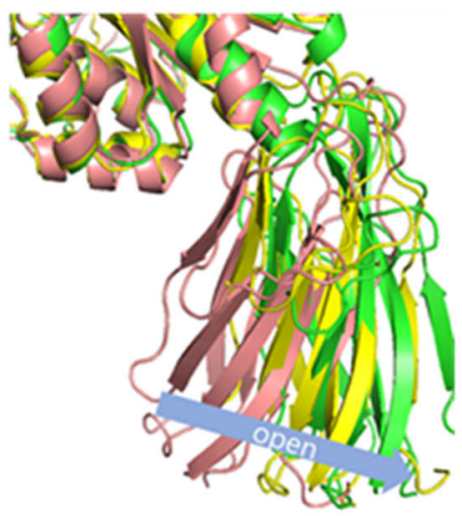

$\mathbf{F}$

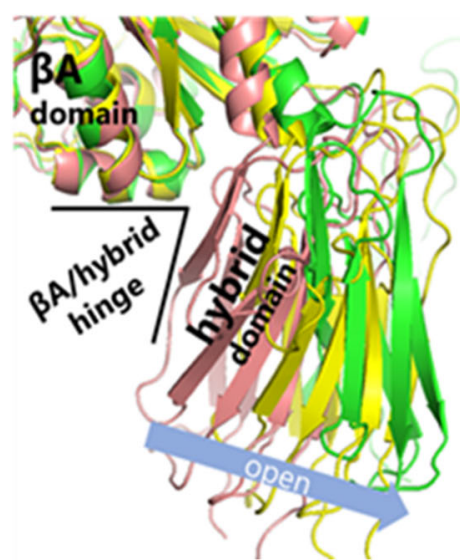

Figure 6. Conformational change of the $\beta A$ /hybrid hinge in $\alpha_{v} \beta_{3}$ integrin. (A) Variation in the $\beta \mathrm{A} /$ hybrid hinge angle as a function of time for integrin binding to RGD on nanoporous gold (NPG). (B) Snapshots of the $\beta$ A/hybrid hinge at 0,5 , and $20 \mathrm{~ns}$ for integrin binding to RGD on NPG. (C) Variation in $\beta A$ /hybrid hinge angle for integrin binding to RGD on flat gold (FG). (D) Snapshots of the $\beta \mathrm{A} /$ hybrid hinge for integrin binding to RGD on FG. (E) Variation in $\beta A$ /hybrid hinge angle for intact integrin. (F) 
Snapshots of the $\beta \mathrm{A} /$ hybrid hinge for intact integrin. In (B), (D), and (F), pink, yellow, and green cartoon structures indicate snapshots at 0,5 , and $20 \mathrm{~ns}$, respectively. 
A

C

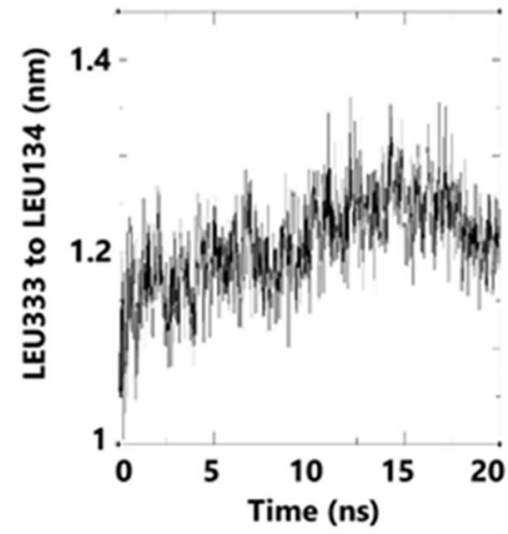

E
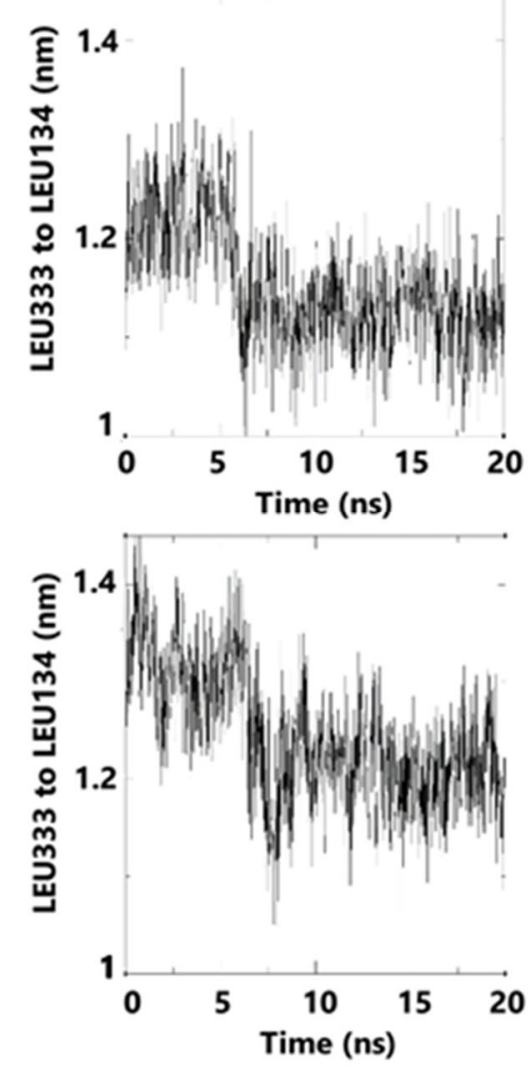

B

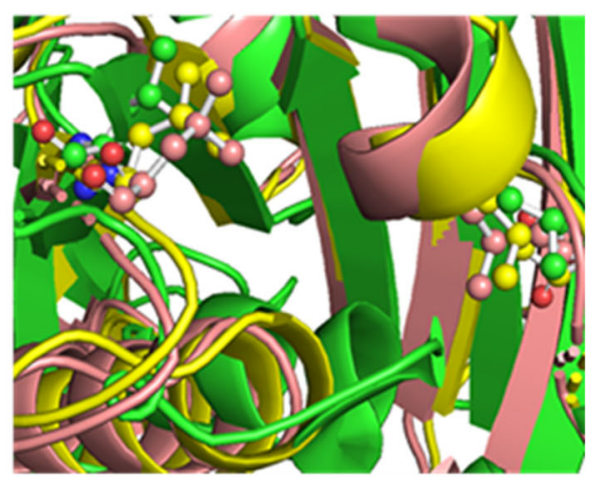

D

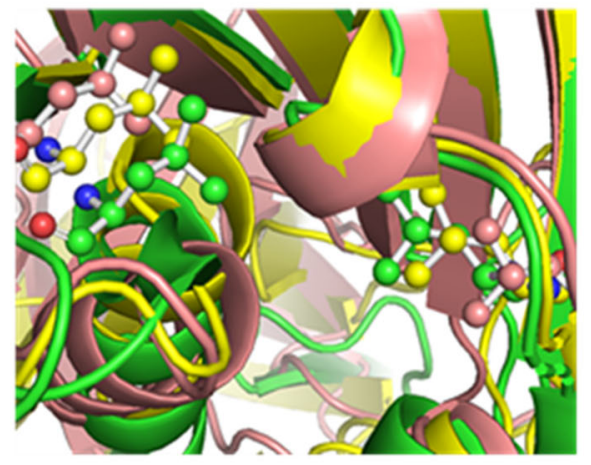

$\mathbf{F}$

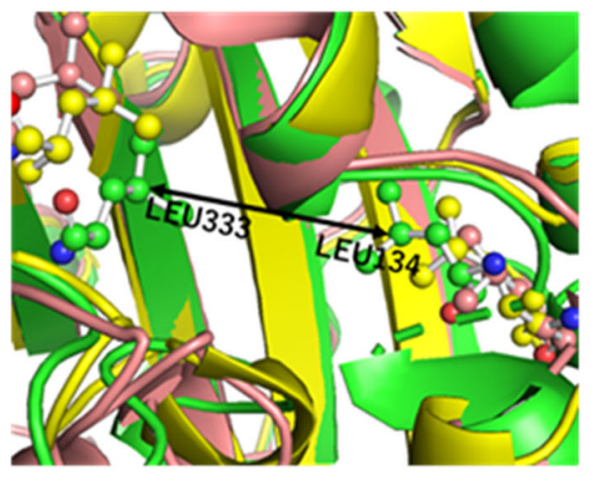

Figure 7. Motion of Leu ${ }^{134}$ of $\alpha 1$ helix and $\operatorname{Leu}^{333}$ of $\beta 6$ strand. (A) Variation in distance between $\mathrm{C} \beta$-atoms of $\mathrm{Leu}^{134}$ and $\mathrm{Leu}^{333}$ in integrin binding to RGD on nanoporous gold (NPG). (B) Snapshots of Leu ${ }^{134}$ and $\mathrm{Leu}^{333}$ at 0, 5, and $20 \mathrm{~ns}$ in integrin binding to RGD on NPG. (C) Variation in distance between Leu ${ }^{134}$ and Leu ${ }^{333}$ in integrin binding to RGD on flat gold (FG). (D) Snapshots of Leu134 and Leu333 in integrin binding to RGD on 
FG. (E) Variation in distance between Leu ${ }^{134}$ and $\mathrm{Leu}^{333}$ in intact integrin. (F) Snapshots of Leu ${ }^{134}$ and Leu ${ }^{333}$ in intact integrin. In (B), (D), and (F), pink, yellow, and green cartoon structures indicate the conformations around $\mathrm{Leu}^{134}$ and $\mathrm{Leu}^{333}$ at 0,5 , and $20 \mathrm{~ns}$, respectively. Leu ${ }^{134}$ and $\mathrm{Leu}^{333}$ are shown as ball and stick models. The black arrow in (F) represents the distance between the $\mathrm{C} \beta$-atoms of $\mathrm{Leu}^{134}$ and $\mathrm{Leu}^{333}$. 


\section{Inactivation of HeLa cells on nanoporous gold - Supplementary Information}

Soichiro Deguchi, Masataka Hakamada*, Jumpei Shingu, Susumu Sakakibara, Hironobu Sugiyama and Mamoru Mabuchi

Department of Energy Science and Technology, Graduate School of Energy

Science, Kyoto University, Yoshidahonmachi, Sakyo, 606-8501 Kyoto,

Japan

*E-mail: hakamada.masataka.3x@kyoto-u.ac.jp. 


\section{RGD / gold (111) surface model in first principles}

\section{calculation}

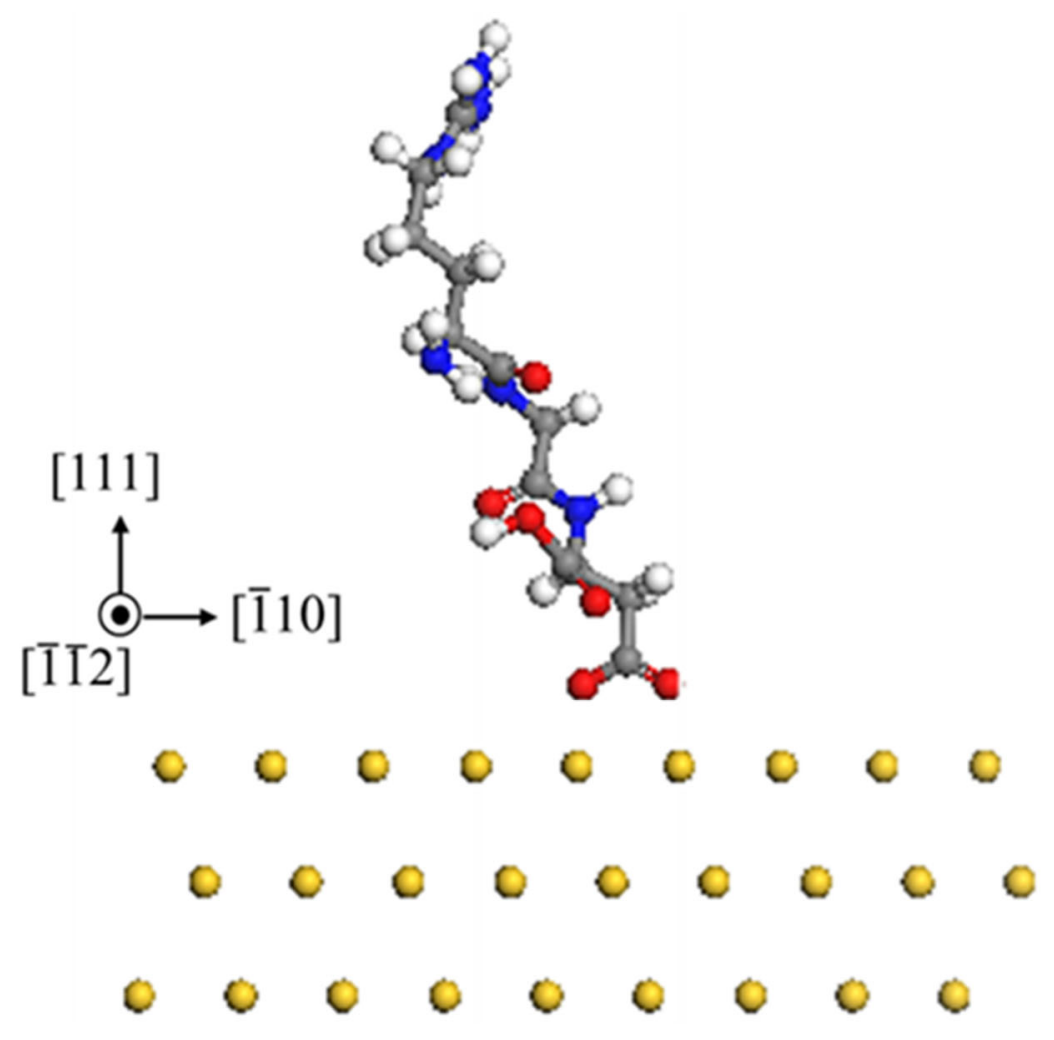

Figure S1. Model of the RGD sequence on a gold (111) surface for first-principle calculations. Red, gray, white, blue, and yellow spheres indicate oxygen, carbon, hydrogen, nitrogen, and gold atoms, respectively. 